\title{
I-NERI Annual Technical Progress Report 2006-002-K, Separation of Fission Products from Molten LiCl-KCI Salt used for Electrorefining of Metal Fuels
}

Steven M. Frank

September 2009

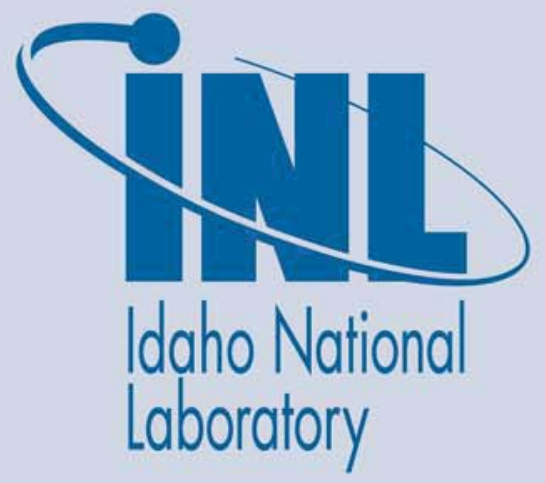

The INL is a U.S. Department of Energy National Laboratory operated by Battelle Energy Alliance 
INL/EXT-09-16903

\section{I-NERI Annual Technical Progress Report 2006-002-K, Separation of Fission Products from Molten LiCl-KCI Salt Used for Electrorefining of Metal Fuels \\ Steven M. Frank}

September 2009

Idaho National Laboratory
Idaho Falls, Idaho 83415

http://www.inl.gov

Prepared for the

U.S. Department of Energy

Office of Nuclear Energy

Under DOE Idaho Operations Office

Contract DE-AC07-05ID14517 


\title{
I-NERI ANNUAL TECHNICAL PROGRESS REPORT
}

Project Number and Title: 2006-002-K, Separation of Fission Products from Molten LiCl-KCl Salt Used for Electrorefining of Metal Fuels

Lead U.S. Investigating Organization: Idaho National Laboratory (INL)

Lead U.S. Principal Investigator: S. Frank

Reporting Period: October 2008 - September 2009

\section{Narrative Subjects:}

Task B1 - Kinetics study for ion exchange between cesium, neodymium and zeolite-A in a molten salt

Task C2 - Integrated fission product separations test with salt from Mark-IV electrorefiner

Task A3.2 Update - Comparison of HFDA Contacting Experiment to Salt/Zeolite Equilibrium Ion Exchange Model

Task C3 - Final separations technology assessment (KAERI/INL)

\begin{abstract}
An attractive alternative to the once-through disposal of electrorefiner salt is to selectively remove the active fission products from the salt and recycle the salt back to the electrorefiner (ER). This would allow salt reuse for some number of cycles before ultimate disposal of the salt in a ceramic waste form. Reuse of ER salt would, thus, greatly reduce the volume of ceramic waste produced during the pyroprocessing of spent nuclear fuel. This final portion of the joint I-NERI research project is to demonstrate the separation of fission products from molten ER salt by two methods previously selected during phase two (FY-08) of this project. The two methods selected were salt/zeolite contacting and rare-earth fission product precipitation by oxygen bubbling. The ER salt used in these tests came from the Mark-IV electrorefiner used to anodically dissolved driver fuel from the EBR-II reactor on the INL site. The tests were performed using the Hot Fuel Dissolution Apparatus (HFDA) located in the main cell of the Hot Fuels Examination Facility (HFEF) at the Materials and Fuels complex on the INL site. Results from these tests were evaluated during a joint meeting of KAERI and INL investigators to provide recommendations as to the future direction of fission product removal from electrorefiner salt that accumulate during spent fuel treatment.
\end{abstract}


Additionally, work continued on kinetic measurements of surrogate quaternary salt systems to provide fundamental kinetics on the ion exchange system and to expand the equilibrium model system developed during the first two phases of this project.

The specific objectives of the FY09 I-NERI research activities at the INL include the following:

- Perform demonstration tests of the selected KAERI precipitation and INL salt/zeolite contacting processes for fission product removal using radioactive, fission product loaded ER salt

- Continue kinetic studies of the quaternary $\mathrm{Cs} / \mathrm{Sr}-\mathrm{LiCl}-\mathrm{KCl}$ system to determine the rate of ion exchange during the salt/zeolite contacting process

- Compare the adsorption models to experimentally obtained, ER salt results

- Evaluate results obtained from the oxygen precipitation and salt/zeolite ion exchange studies to determine the best processes for selective fission-product removal from electrorefiner salt.

Task B1. Kinetics Study for Ion Exchange between Cesium, Stronium and Zeolite$A$ in a Molten Salt

\section{B1.1 Introduction}

At the Idaho National Laboratory (INL), in a process known as pyroprocessing of spent nuclear fuel, one of the important steps is relating to the removal process of the spent electrolyte, consisting of $\mathrm{LiCl}, \mathrm{KCl}, \mathrm{NaCl}$, various actinide chlorides, and various fission product chlorides. They must be periodically removed from the electrorefiner and combined with zeolite-4A (LTA) and glass to form a ceramic waste form. Currently, methods are being investigated for chemically reducing the actinide chlorides prior to combining the salt with the zeolite to prevent the actinides from being discarded in the ceramic waste stream. In the baseline process, excess zeolite-4A is used so that all of the salt is absorbed into its alpha cages. However, this is seen as a wasteful approach, since useful $\mathrm{LiCl}-\mathrm{KCl}$ is thrown away in addition to the $\mathrm{NaCl}$ and fission product chlorides (Ref. 1). If a selective ion exchange material was used, waste volume reduction could potentially be realized. An ion exchange process has, thus, been proposed for minimizing ceramic waste volume generated from the pyroprocessing method for treating spent nuclear fuel. One viable approach is that a zeolite ion exchange column could be implemented to remove any contaminants from the $\mathrm{LiCl}-\mathrm{KCl}$ and allow the cleaned salt to be recycled back to the electrorefiner (Ref. 2).

Zeolite-A has been proposed to selectively remove fission products from the $\mathrm{LiCl}-\mathrm{KCl}$ based electrolyte. For this reason, the nature of the interactions between various molten chloride salts and zeolite-A is of great interest. And predictive information is necessary to help design and optimize an ion exchange process. In general, two processes occur when molten salts and zeolite come in to contact: (1) molten salt occlusion to form salt-loaded zeolite, and (2) ion exchange between the molten salt and salt-loaded zeolite (Ref. 3) 
Previous experimental work on ion exchange between zeolite-A and molten chloride salts has been almost entirely focused on the equilibrium condition (Refs. 4-6). As a result, fundamental kinetics information essential for design and operation analysis of this process is lacking. The main scope of this study is, thus, to explore kinetics of this ion exchange system.

\section{B1.2 Projection Description}

In support of the Advanced Fuel Cycle Initiative (AFCI) and the Global Nuclear Energy Partnership (GNEP), this project aimed to experimentally study the kinetics of chemical reactions taking place in the form of ion exchange between multivalent cations and zeolite A. Experiments were conducted and worked in compliance with INL policies to obtain experimental data sets and develop kinetic models. This work focuses on the study of ternary $\mathrm{CsCl}-\mathrm{LiCl}-\mathrm{KCl}$ and $\mathrm{SrCl}_{2}-\mathrm{LiCl}-\mathrm{KCl}$ systems.

\section{Mathematical Background}

In this study, three different approaches have been used to analyze the experimental data sets: (1) chemical kinetics limited, (2) mass transfer limited, and (3) forwarding reaction technique. The difference between the first two cases is in fact that the first model is based on independent order reaction kinetics which can be obtained from empiricism while the later model provides an aspect of the $1^{\text {st }}$ order reaction kinetics. For the chemical kinetics-limited case, it is based on the reaction condition that the rate is mainly a function of the concentration of only one reactant; that is, for the decomposition reaction, $\mathrm{A} \rightarrow$ products. The last approach is based on determining the rate constant of the forwarding reaction reported by Phongikaroon and Simpson (Ref. 7).

For the chemical kinetics approach, let A stands for Cs species. Then, it can be shown using a general rate law based on concentration of the species $\left(\mathrm{C}_{\mathrm{A}}\right)$, which can be expressed as

$$
-\frac{\mathrm{dC}}{\mathrm{dt}}=\mathrm{kC}_{\mathrm{A}}^{\mathrm{a}}
$$

where $\mathrm{t}$ is the reaction time, $\mathrm{k}$ is the rate constant and $\mathrm{a}$ is the order of the reaction rate. It is possible to take the natural logarithm of Eq. [1] and the result becomes

$$
\ln \left(-\frac{d C_{A}}{d t}\right)=\ln k+a \ln C_{A}
$$

The value of $\mathrm{dC}_{\mathrm{A}} / \mathrm{dt}$ can be calculated using the three-point differentiation technique (Ref. 8):

$$
\left(\frac{\mathrm{dC}}{\mathrm{dt}}\right)_{\mathrm{t}_{0}}=\frac{-3 \mathrm{C}_{0}+4 \mathrm{C}_{1}-\mathrm{C}_{2}}{2 \Delta \mathrm{t}},\left(\frac{\mathrm{dC}}{\mathrm{dt}}\right)_{\mathrm{t} 1}=\frac{\mathrm{C}_{2}-\mathrm{C}_{0}}{2 \Delta \mathrm{t}},\left(\frac{\mathrm{dC}}{\mathrm{dt}}\right)_{\mathrm{t}_{2}}=\frac{\mathrm{C}_{0}-4 \mathrm{C}_{1}+3 \mathrm{C}_{2}}{2 \Delta \mathrm{t}}
$$

where subscript of $\mathrm{C}$ designated the order of the concentration order in the data set. The $\ln \left(-\mathrm{dC}_{\mathrm{A}} / \mathrm{dt}\right)$ versus $\ln \left(\mathrm{C}_{\mathrm{A}}\right)$ plot gives the information about order and rate constant of the reaction. The slope value is equivalent to the reaction order while the intercept value signifies the value of $\ln (\mathrm{k})$. 
Alternatively, the problem can be approached with the assumption that the situation is the mass transfer limited. In this case, diffusion coefficient (D) can be related to the exchanged amount of each species at any given time ( $\mathrm{Q}_{\mathrm{t}}$ (Refs. 3 and 4):

$$
\mathrm{Q}_{\mathrm{t}} / \mathrm{Q}_{\infty}=\frac{6}{\mathrm{r}} \sqrt{\frac{\mathrm{Dt}}{\pi}}
$$

where $\mathrm{Q}_{\infty}$ is the exchanged amount at equilibrium, and $\mathrm{r}$ is the radius of the zeolite particle. By analyzing the near time-zero slope of Eq. [4], the value of D can be related to a rate constant $(\mathrm{K})$ by plotting $\mathrm{Q}_{t} / \mathrm{Q}_{\infty}$ versus $\mathrm{t}^{1 / 2}$; that is

$$
\mathrm{K}=\frac{6}{\mathrm{r}} \sqrt{\frac{\mathrm{D}}{\pi}}
$$

Moreover, by dimensional inspection, it can be seen that $\mathrm{K}^{2}$ has the dimension of (time) ${ }^{-1}$ showing that the kinetics reaction associates with the first order reaction rate under the mass transfer limited.

The third approach can also be used to determine the rate constants $\mathrm{k}$. Here, $\mathrm{k}_{\mathrm{i}}$ is the forwarding rate constant of species i of the reaction type presented by Ref. 7 :

$$
\left(\mathrm{M}_{\mathrm{i}}^{\left(\mathrm{n}_{\mathrm{i}}\right)^{+}}\right)_{\mathrm{s}}+\mathrm{n}_{\mathrm{i}}\left(\mathrm{Li}^{+}\right)_{\mathrm{z}} \leftrightarrow\left(\mathrm{M}_{\mathrm{i}}^{\left(\mathrm{n}_{\mathrm{i}}\right)^{+}}\right)_{\mathrm{z}}+\mathrm{n}_{\mathrm{i}}\left(\mathrm{Li}^{+}\right)_{\mathrm{s}}
$$

By using this reaction process, it is assumed that the interested species in the salt phase is exchanging with the lithium in the zeolite phase and the forwarding reaction can be expressed as

$$
\mathrm{r}_{\mathrm{f}, \mathrm{i}}=-\mathrm{k}_{\mathrm{i}} \mathrm{x}_{\mathrm{i}}\left(\mathrm{y}_{\mathrm{Li}}\right)^{\mathrm{n}_{\mathrm{i}}}
$$

where $x_{i}$ is the mole fraction of species $i$ in the salt phase, $y_{\mathrm{Li}}$ is the moles of lithium per mole of zeolite pseudo unit cell (in the zeolite phase), and $\mathrm{n}_{\mathrm{i}}$ is the charge of the exchangeable cation $\mathrm{i}$. In this scenario, $\mathrm{y}_{\mathrm{Li}}$ can be calculated based on the following formula:

$$
\mathrm{y}_{\mathrm{Li}}=\frac{12\left[\mathrm{n}_{\mathrm{i}} \cdot(\mathrm{wt} \%)_{\mathrm{i}} / \mathrm{MW}_{\mathrm{i}}\right]}{\left[(\mathrm{wt} \%)_{\mathrm{Al}} / \mathrm{MW}_{\mathrm{Al}}\right]}
$$

where $\mathrm{wt} \%{ }_{\mathrm{i}}$ and $\mathrm{MW}_{\mathrm{i}}$ are the weight percent and the molecular weight of species $\mathrm{i}$ in the zeolite; the subscript $\mathrm{Al}_{\mathrm{l}}$ stands for aluminum. It is important to note that although the reaction presented by Eq. [6] may not be appropriate because it was based on the equilibrium condition, the approach is applied based on a possible exchange between the interested species to the lithium ion due to the fact that lithium has the smallest ionic radius in comparison to other species.

Thus, Eq. [7] can be solved to obtain the $\mathrm{x}_{\mathrm{i}}$ as a function of time. The result after setting $\mathrm{r}_{\mathrm{f}, \mathrm{i}}=\mathrm{dx}_{\mathrm{i}} / \mathrm{dt}$, and integrating with the initial condition of $\mathrm{x}_{\mathrm{i}}=\mathrm{x}_{\mathrm{io}}$ at time $\mathrm{t}=0$ yields

$$
\ln \left(\mathrm{x}_{\mathrm{i}}(\mathrm{t})\right)=-\mathrm{k}_{\mathrm{i}}\left(\mathrm{y}_{\mathrm{Li}}\right)^{\mathrm{n}_{\mathrm{i}}} \mathrm{t}+\ln \left(\mathrm{x}_{\mathrm{io}}\right)
$$

The value of $\mathrm{k}_{\mathrm{i}}$ can be obtained by plotting $\ln \left(\mathrm{x}_{\mathrm{i}}(\mathrm{t})\right)$ against $\mathrm{t}$. The disadvantage of using Eq. [9] is that it requires both the information from the salt and zeolite phases.

In addition to all the kinetic approaches, the distribution coefficient $(\delta)$ of each species can be determined by 


$$
\delta_{\mathrm{i}}=\mathrm{x}_{\mathrm{i}(\mathrm{z})} / \mathrm{x}_{\mathrm{i}(\mathrm{s})}
$$

where the subscript ${ }_{i}$ stands for exchanged species, and $\mathrm{x}_{\mathrm{i}(z)}$ and $\mathrm{x}_{\mathrm{i}(\mathrm{s})}$ are the moles of species $\mathrm{i}$ in zeolite and salt phases, respectively. By plotting the value of $\delta$ versus exchanged concentration, the standard chemical potentials of that species reaction $\left(\Delta \mu_{\mathrm{i}}\right)$ can be calculated using the following expression:

$$
\Delta \mu_{\mathrm{i}}=-\mathrm{RT} \ln \left(\delta_{\mathrm{i}}^{\infty}\right)
$$

where $\mathrm{R}$ is the universal gas constant, $\mathrm{T}$ is the system temperature, and $\delta_{i}^{\infty}$ is the distribution coefficient of the species at infinite dilution. This calculation is used mainly for validating the experiments showing the extrapolation of kinetics data close to the equilibrium stage can be help to predict the equilibrium condition.

\section{B1.3 Experimental Routines and Sample Analysis}

$\mathrm{CsCl}$ and $\mathrm{SrCl}_{2}$ were selected as the primary species for the first phase of this study. All experiments were conducted at $500{ }^{\circ} \mathrm{C}$. Different concentrations $(0.5,1.0$, 1.5 , and $2.0 \mathrm{~mol} \%$ ) of $\mathrm{CsCl}$ were selected to examine the concentration effect on kinetics. The samples of the salt and zeolites phases were taken every 5 minutes interval up to 25 minutes time frame because cesium reaches its equilibrium stage after approximately 30 minutes (Refs. 4 and 6). Here, $11.5 \mathrm{~g}$ of $\mathrm{LiCl}-\mathrm{KCl}$ eutectic salt was added to a magnesia crucible and $1.5 \mathrm{~g}$ of dried zeolite was weighed out and added to an iron mesh basket.

Different concentrations $(0.2,0.3,0.4$, and $0.5 \mathrm{~mol} \%)$ of $\mathrm{SrCl}_{2}$ were selected to examine the concentration effect on kinetics. Strontium reaches at its equilibrium stage approximately after $3 \mathrm{hrs}$ (Ref. 4). The samples of salt and zeolite phases were taken every 30 minutes interval up to $6 \mathrm{hrs}$ in the first experiment, to observe the time to reach the equilibrium stage. Otherwise, all the other samples for other experiments were taken at the same interval up to 3 hours. In these experimental sets, $23 \mathrm{~g}$ of $\mathrm{LiCl}-\mathrm{KCl}$ eutectic salt was added to a magnesia crucible while $3 \mathrm{~g}$ dried zeolite was weighed out and added to an iron mesh basket. All samples were loaded into the furnace inside the argon gas glovebox environment, as shown in Figure B1.3.1.

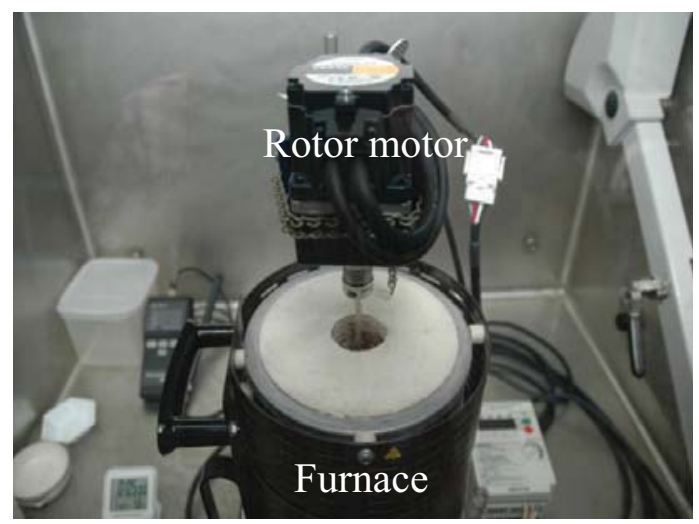

Figure B1.3.1. Ion exchange experimental setup inside the Labconco glovebox 
To prepare a salt sample dissolution, approximately $0.03 \mathrm{~g}$ salt was dissolved in 1 $\mathrm{mL}$ of $2 \%$ by volume of $(50 \%-70 \%) \mathrm{HNO}_{3}$. To dissolve zeolite samples, $500 \mu \mathrm{L}$ of (32$38 \%) \mathrm{HCl}, 500 \mu \mathrm{L}\left(50-70 \%\right.$ vol) $\mathrm{HNO}_{3}$, and $300 \mu \mathrm{L}(48-52 \%) \mathrm{HF}$ were added to each test tube containing $0.03 \mathrm{~g}$ of zeolite. The zeolite was allowed to dissolve for 30 minutes and then was warmed on a hot plate for an additional 15 minutes. Then $4 \mathrm{~mL}$ of $2.2 \%$ boric acid $+0.2 \%$ EDTA solution was added to the test tube. The new solution was heated on the hot plate for another 15 minutes and then diluted to approximately $10 \mathrm{ml}$ using nano-pure water. The samples from all $\mathrm{CsCl}$ and $\mathrm{SrCl}_{2}$ runs were analyzed right after each run, and the entire dissolution process followed the above procedures. It should be mention that there was no analysis on the zeolite samples for the $\mathrm{CsCl}$ experiments.

The zeolite samples had to be crushed and rinsed before the digestion was performed. The zeolite pellets were crushed between two square disposable weighing dishes. After crushing, the zeolite was rinsed using a vacuum filter apparatus. A course filter paper was utilized for the task. Nanopure water was used as the rinsing agent and each zeolite sample was rinsed three times. After crushing and rinsing, the zeolite samples were placed in test tubes and weighed.

In addition to the salt and zeolite samples, blank samples were prepared for comparison to the experiment samples. A lithium-zeolite blank, Li-K salt/Li-zeolite blank, and a Li-zeolite/acid blank were weighed in the same fashion as the other samples. Solutions were then analyzed using ICP-MS. For the salt solutions, $10 \mu \mathrm{L}$ of sample was transferred into two different test tubes. One test tube was diluted by 100 times for analyzing $\mathrm{Na}$, and the other was diluted by 10,000 times for analyzing $\mathrm{Li}, \mathrm{K}, \mathrm{Cs}$, and $\mathrm{Sr}$. Zeolite samples were diluted by 1000 times and analyzed for $\mathrm{Na}, \mathrm{Li}, \mathrm{K}, \mathrm{Cs}$, and $\mathrm{Sr}$.

\section{B1.4 Results and Discussion}

The chemical kinetics limited model was used to analyze the data from the $\mathrm{CsCl}$ experiments. The results for $0.5 \mathrm{~mol} \% \mathrm{CsCl}$ study are shown in Figures B1.4.1(A) and 2(B) to illustrate the technique. The dash-line drawn in Figure B1.4.1 (B) indicates the fitted linear to the data set while the solid-lines represent the round off of the slope to the nearest integer. The value of $\mathrm{k}$ is determined from the round off slope line. The analyzed and compared results for all $\mathrm{CsCl}$ studies are listed in Table B1.4.1. The results show that the rate constant decreases as the concentration increases and the reaction order is ranging from 3 rd to 5 th.
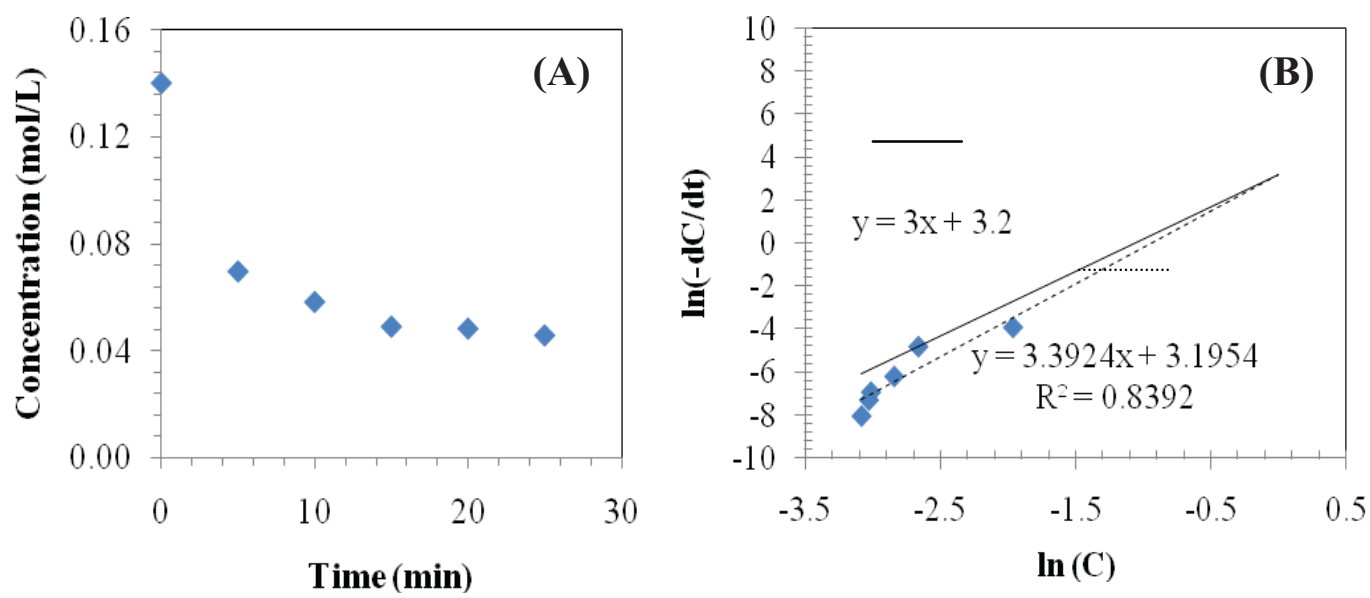
Figure B1.4.1. (A) Resulting plot of Cs concentration in salt, and (B) Slope Plot using kinetics approach for $0.5 \mathrm{~mol} \% \mathrm{CsCl}$ condition

Table B1.4.1. List of reaction orders and rate constants for Cs using the kinetics approach.

\begin{tabular}{|c|c|c|}
\hline CsCl concentration (mol\%) & Reaction order, a & Rate constant, k \\
\hline 0.5 & 3 & $0.36(\mathrm{~L} / \mathrm{mol})^{2} / \mathrm{sec}$ \\
\hline 1.0 & 4 & $0.20(\mathrm{~L} / \mathrm{mol})^{3} / \mathrm{sec}$ \\
\hline 1.5 & 4 & $0.05(\mathrm{~L} / \mathrm{mol})^{3} / \mathrm{sec}$ \\
\hline 2.0 & 5 & $0.03(\mathrm{~L} / \mathrm{mol})^{4} / \mathrm{sec}$ \\
\hline
\end{tabular}

Figures B1.4.2(A) and B1.4.2(B) illustrates the resulting plot of $0.2 \mathrm{~mol} \% \mathrm{SrCl}_{2}$ condition. Similar approach has been applied to determine the $\mathrm{k}$ value. The value of $\mathrm{k}$ is scattered for different concentration and there is no pattern to detect for the strontium. However, the results indicate that strontium has the $6^{\text {th }}$ order reaction consuming higher than the cesium. In addition, the resulting $\mathrm{k}$ for strontium is higher than the values obtained for cesium. All results are listed in Table B1.4.2.
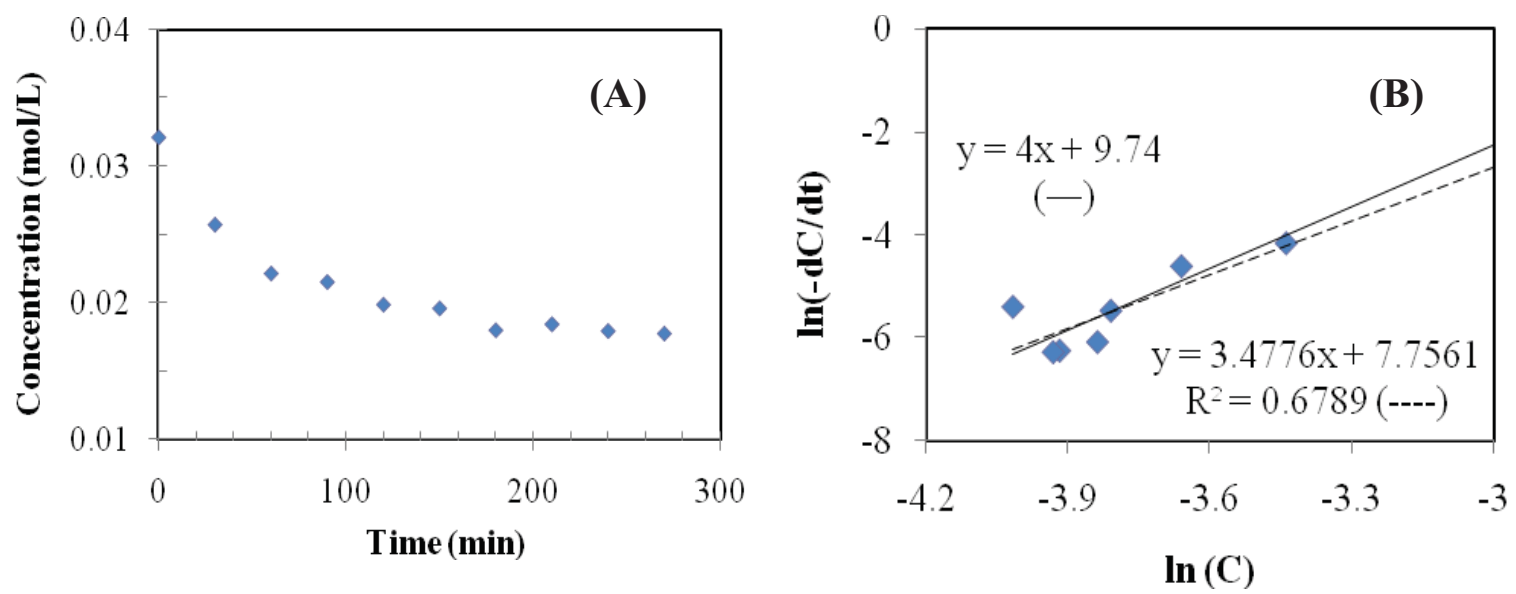

Figure B1.4.2. (A) Resulting plot of Sr concentration in salt, and (B) Slope Plot using kinetics approach for $0.2 \mathrm{~mol} \% \mathrm{SrCl}_{2}$ condition

Table B1.4.2. List of reaction orders and rate constants for $\mathrm{Sr}$ using the kinetics approach and the forward reaction technique

\begin{tabular}{|c|c|c|c|}
\hline $\begin{array}{c}\mathbf{S r C l}_{2} \text { concentration } \\
(\mathbf{m o l} \%)\end{array}$ & $\begin{array}{c}\text { Reaction } \\
\text { order, } \mathbf{a}\end{array}$ & Rate constant, $\mathbf{k}$ & $\begin{array}{c}\text { Forwarding rate } \\
\text { constant, } \mathbf{k}_{\mathbf{S r}}\end{array}$ \\
\hline 0.2 & 4 & $0.68(\mathrm{~L} / \mathrm{mol})^{3} / \mathrm{sec}$ & $0.014 \pm 2.19 \mathrm{E}-5 \mathrm{sec}^{-1}$ \\
\hline 0.3 & 6 & $91.04(\mathrm{~L} / \mathrm{mol})^{5} / \mathrm{sec}$ & $0.0093 \pm 6.22 \mathrm{E}-5 \mathrm{sec}^{-1}$ \\
\hline 0.4 & 6 & $16.63(\mathrm{~L} / \mathrm{mol})^{5} / \mathrm{sec}$ & $0.0096 \pm 5.16 \mathrm{E}-5 \mathrm{sec}^{-1}$ \\
\hline 0.5 & 6 & $1.84(\mathrm{~L} / \mathrm{mol})^{5} / \mathrm{sec}$ & $0.0099 \pm 6.06 \mathrm{E}-5 \mathrm{sec}^{-1}$ \\
\hline
\end{tabular}


For the strontium studies, the forwarding reaction technique is applied in order to find or observe the pattern of the overall kinetics. Figure B1.4.3 (A) shows the plot of $\ln \left(\mathrm{x}_{\mathrm{Sr}}\right)$ as a function of time, $\mathrm{t}$ up to 180 minutes for the $0.2 \mathrm{~mol} \% \mathrm{SrCl}_{2}$ condition. It can be seen that there is a steep increment during the first 60 minutes of the experiment. This slope indicates the real kinetics on the ion exchange process and the focusing region at this time frame is shown in Figure B1.4.3 (B). Eq. [9] is applied to these data points to extract the $\mathrm{k}_{\mathrm{Sr}}$ value. The results are listed in Table 2 for comparison with the first approach. The $\mathrm{k}_{\mathrm{Sr}}$ values are about $0.01 \mathrm{sec}^{-1}$ for all experiments; they show a stable trend in comparison to the values from the first approach. However, it is important to keep in mind that this is based on the kinetics exchange between the strontium ions with lithium ions only. In reality, there may be other exchanges between strontium ions and other component ions. Nevertheless, the results using this technique indicate the stable trend of the forwarding rate constant.
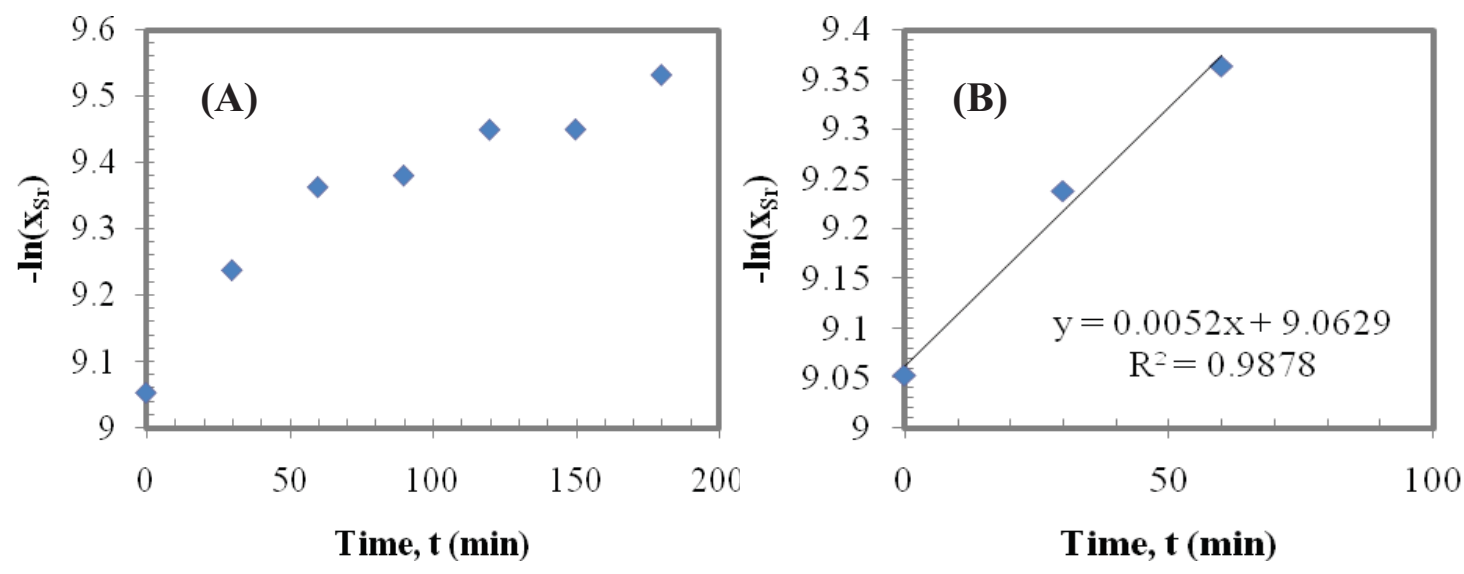

Figure B1.4.3. (A) Resulting plot of Sr concentration in salt, and (B) Slope Plot using kinetics approach for $0.2 \mathrm{~mol} \% \mathrm{SrCl}_{2}$ condition

Aside from using the $1^{\text {st }}$ and the $3^{\text {rd }}$ approach, the mass transfer limited model has been applied to both data sets. The value of $\mathrm{D}$ and $\mathrm{K}$ were determined by using Eqs. [4] and [5]. Figure B1.4.4 shows the plot of $\mathrm{Q}_{\mathrm{t}} / \mathrm{Q}_{\infty}$ versus $\mathrm{t}^{1 / 2}$ for the $0.2 \mathrm{~mol} \% \mathrm{CsCl}$ and 0.2 $\mathrm{mol} \% \mathrm{SrCl}_{2}$ conditions as an example. The first three data points were fitted to determine the value of D. The value of $r$ in Eq. [4] is chosen to be $0.1 \mathrm{~cm}$ based on Ref. [4].
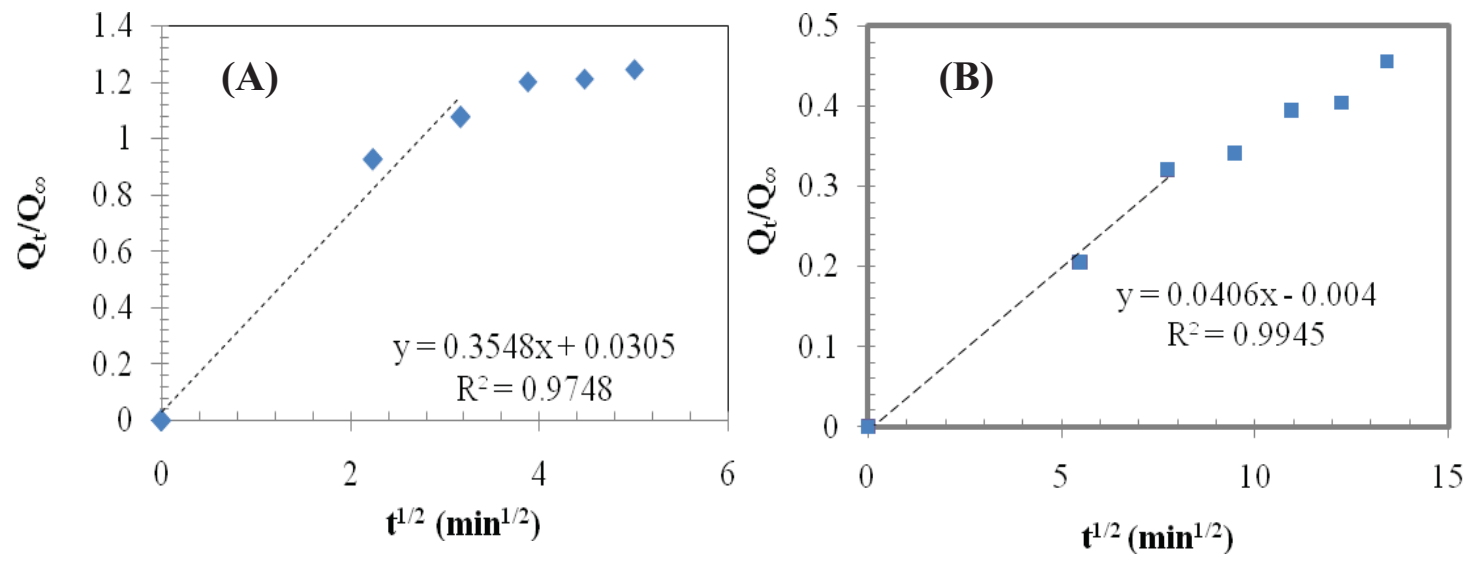


\section{Figure B1.4.4. Plot of $Q_{t} / Q_{\text {inf }}$ versus $\mathrm{t}^{1 / 2}$ for (A) $0.2 \mathrm{~mol} \% \mathrm{CsCl}$, and (B) $0.2 \mathrm{~mol} \%$ $\mathrm{SrCl}_{2}$ conditions}

Tables B1.4.3 and B1.4.4 provide the values of $\mathrm{D}$ and $\mathrm{K}$ determined for $\mathrm{Cs}$ and Sr. The values of D follow in the same order of magnitude for liquid-solid diffusion coefficient. Aside from the $1.5 \mathrm{~mol} \% \mathrm{CsCl}$ data points, the results show that both $\mathrm{D}$ and $\mathrm{K}$ increase as concentration increases. Similarly, at higher concentration of $\mathrm{SrCl}_{2}$, it appears that the $\mathrm{K}^{2}$ values remain in around $0.0002 \mathrm{sec}^{-1}$.

Table B1.4.3. List of $\mathrm{D}\left(\mathrm{cm}^{2} / \mathrm{sec}\right)$ and $K^{2}(1 / \mathrm{sec})$ for Cs

\begin{tabular}{|c|c|c|}
\hline CsCl concentration (mol\%) & $\mathbf{D}$ & $\mathbf{K}^{\mathbf{2}}$ \\
\hline 0.5 & $2.97 \times 10^{-8}$ & $2.00 \times 10^{-3}$ \\
\hline 1.0 & $8.71 \times 10^{-8}$ & $1.21 \times 10^{-2}$ \\
\hline 1.5 & $1.60 \times 10^{-8}$ & $1.39 \times 10^{-3}$ \\
\hline 2.0 & $2.43 \times 10^{-7}$ & $1.74 \times 10^{-2}$ \\
\hline
\end{tabular}

Table B1.4.4. List of $D\left(\mathrm{~cm}^{2} / \mathrm{sec}\right)$ and $K^{2}(1 / \mathrm{sec})$ for $\mathrm{Sr}$

\begin{tabular}{|c|c|c|}
\hline $\mathbf{S r C l}_{\mathbf{2}}$ concentration (mol\%) & $\mathbf{D}$ & $\mathbf{K}^{\mathbf{2}}$ \\
\hline 0.2 & $2.48 \times 10^{-8}$ & $8.61 \times 10^{-5}$ \\
\hline 0.3 & $1.40 \times 10^{-7}$ & $2.11 \times 10^{-4}$ \\
\hline 0.4 & $1.75 \times 10^{-7}$ & $2.36 \times 10^{-4}$ \\
\hline 0.5 & $2.37 \times 10^{-7}$ & $2.75 \times 10^{-4}$ \\
\hline
\end{tabular}

The distribution coefficients for all samples of $\mathrm{Cs}$ and $\mathrm{Sr}$ were calculated and the results are shown in Table B1.4.5 and B1.4.6 $\delta_{\mathrm{Cs}}$ increases with time and decreases as $\mathrm{CsCl}$ and $\mathrm{SrCl}_{2}$ concentration increases. Approximately $50 \%$ to $70 \%$ of $\mathrm{Cs}$, and about $40 \%$ of $\mathrm{Sr}$ is separated from molten salt within half and three hours, respectively. The standard chemical potential, $\Delta \mu_{\mathrm{CS}}$, for Cs and Sr ion-exchange was calculated by plotting $\delta_{\mathrm{Cs}}$ versus concentration of $\mathrm{Cs}$ and $\mathrm{Sr}$ in salt phase to obtain the value of $\delta_{\mathrm{Cs}}^{\infty}$.

Additionally, the values of $\Delta \mu_{\mathrm{Cs}}$ and $\Delta \mu_{\mathrm{Sr}}$ were calculated using Eq. [11]; these are listed in Tables 5 and 6 for cesium and strontium, respectively. The average value of $\Delta \mu_{\mathrm{Cs}}$ is $-5.43 \pm 0.81 \mathrm{~kJ} / \mathrm{mol}$; this value is in the same order reported by Ref. [4] for CsCl study in molten $\mathrm{LiCl}-\mathrm{KCl}$. The average value of $\Delta \mu_{\mathrm{Sr}}$ is $-17.64 \pm 0.39 \mathrm{~kJ} / \mathrm{mol}$. It is shown that the kinetics experimental results can be used to extrapolate to predict the equilibrium information.

\section{B1.5 Conclusions}

The kinetics studies of $\mathrm{LiCl}-\mathrm{KCl}-\mathrm{CsCl}$ and $\mathrm{LiCl}-\mathrm{KCl}-\mathrm{SrCl}_{2}$ systems have been accomplished. The results show that $\mathrm{Cs}$ reaches at its equilibrium after approximately 25 minutes, and $\mathrm{Sr}$ approximately after 120 minutes agreeing with an observation reported by Refs. 4, 6, and 7. Kinetics and diffusion-limited models have been applied to analyze 
the data sets of $0.5,1.0,1.5,2.0 \mathrm{~mol} \% \mathrm{CsCl}$, and $0.2,0.3,0.4,0.5 \mathrm{~mol}_{0} \mathrm{SrCl}_{2}$. In addition, the forwarding reaction technique has been used to analyze the strontium data sets. For the kinetics approach, three-point differentiation technique has been applied to determine reaction order and specific reaction rate. The results reveal that the depletion of Cs from the salt phase behaves overall like a $4^{\text {th }}$ order reaction while the depletion of Sr behaves overall like a $6^{\text {th }}$ order reaction. There is no distinctive trend to describe the kinetics based on the first approach. However, using the third approach reveal a stable trend of $\mathrm{k}$ for the strontium experiment.

For the diffusion-limited approach, diffusion coefficient and rate constant generally increase as $\mathrm{CsCl}$ and $\mathrm{SrCl}_{2}$ concentration increases. The results show that the diffusion coefficients are in the same order of magnitude for liquid-solid diffusion coefficient for other systems. The chemical potentials for $\mathrm{Cs}$ and $\mathrm{Sr}$ ion exchange reactions were calculated to be $-5.43 \pm 0.81 \mathrm{~kJ} / \mathrm{mol}$ and $-17.64 \pm 0.39 \mathrm{~kJ} / \mathrm{mol}$, respectively. By calculating the distribution ratios, it was observed that $50-70 \%$ of $\mathrm{Cs}$ and about $40 \%$ of $\mathrm{Sr}$ can be separated from molten salt within less than 30 minutes and 180 minutes, respectively.

\section{$\underline{\text { Future Tasks }}$}

Investigation of cesium chloride $(\mathrm{CsCl})$, strontium chloride $\left(\mathrm{SrCl}_{2}\right)$, and neodymium $\left(\mathrm{NdCl}_{3}\right)$ ion exchange kinetics for quaternary systems has been initiated together, and will be continued in FY09-10. Rare earth elements will be studied to help understanding the optimization of waste via ion exchange process. The data for all the sets of experiments will be analyzed using all three approaches. Rate constants, reaction order, and reaction rates will be obtained to lead to a better understanding of transfer rate of species into zeolites. Diffusion coefficient, distribution coefficient, and chemical potential of different species ion-exchange reaction will be determined from modeling based on the diffusion-limited approach.

\section{Table B1.4.5. Distribution coefficient of Cs as a function of time and chemical potential}

\begin{tabular}{|c|c|c|c|c|}
\hline \multirow{2}{*}{ Time (min) } & \multicolumn{4}{|c|}{ Distribution coefficient } \\
\cline { 2 - 5 } & $\mathbf{0 . 5} \mathbf{~ m o l \%}$ & $\mathbf{1 . 0} \mathbf{~ m o l \%}$ & $\mathbf{1 . 5} \mathbf{~ m o l \%}$ & $\mathbf{2 . 0} \mathbf{~ m o l \%}$ \\
\hline 0 & 0 & 0 & 0 & 0 \\
\hline 5 & 1.01 & 0.83 & 0.87 & 0.55 \\
\hline 10 & 1.40 & 1.10 & 1.17 & 0.78 \\
\hline 15 & 1.85 & 1.16 & 1.29 & 0.95 \\
\hline 20 & 1.89 & 1.26 & 1.36 & 1.07 \\
\hline 25 & 2.05 & 1.37 & 1.58 & 1.13 \\
\hline Infinite & 2.78 & 2.19 & 2.43 & 2.01 \\
\hline
\end{tabular}




\begin{tabular}{|l|l|l|l|l|}
\hline$\Delta \mu_{\mathrm{Cs}}(\mathrm{kJ} / \mathrm{mol})$ & -6.4 & -5.1 & -5.7 & -4.5 \\
\hline
\end{tabular}

Table B1.4.6. Distribution coefficient of $\mathrm{Sr}$ as a function of time and chemical potential

\begin{tabular}{|c|c|c|c|c|}
\hline \multirow{2}{*}{ Time (hr) } & \multicolumn{4}{|c|}{ Distribution coefficient } \\
\hline & $0.2 \mathrm{~mol} \%$ & $0.3 \mathrm{~mol} \%$ & $0.4 \mathrm{~mol} \%$ & $0.5 \mathrm{~mol} \%$ \\
\hline 0.0 & 0 & 0 & 0 & 0 \\
\hline 0.5 & 4.45 & 3.22 & 4.50 & 4.07 \\
\hline 1.0 & 5.50 & 4.57 & 5.53 & 6.82 \\
\hline 1.5 & 5.20 & 5.09 & 6.04 & 7.70 \\
\hline 2.0 & 5.68 & 4.49 & 4.88 & 5.60 \\
\hline 2.5 & 5.15 & 3.98 & 4.64 & 5.01 \\
\hline 3.0 & 6.17 & 4.26 & 4.20 & 5.31 \\
\hline Infinite & 16.09 & 15.02 & 14.61 & 16.60 \\
\hline$\Delta \mu_{\mathrm{Sr}}(\mathrm{kJ} / \mathrm{mol})$ & -17.86 & -17.41 & -17.23 & -18.06 \\
\hline
\end{tabular}

\section{$\underline{\text { References }}$}

1. Simpson MF, Goff KM, Johnson SG, Batemen KJ, Battisti TJ, Toews KL, Frank SM, Moschetti TL, and O'Holleran TP. A Description of the Ceramic Waste Form Production Process from the Demonstration Phase of the Electrometallurgical Treatment of EBR-II Spent Fuel. Nuclear Technology 2001; 134: 263-277.

2. Pereira C, Hash MC, Lewis MA, Richmann MK, Basco J. Incorporation of Radionuclides from the Electrometallurgical Treatment of Spent Fuel into a Ceramic Waste Form. Mater. Res. Soc. Symp. Proc. 1999; 556: 115-120.

3. Breck DW. Zeolite Molecular Sieves. Malabar, Florida: Krieger Publishing Company; 1984, pp. 530-539.

4. Lexa D, Johnson I. Occlusion and Ion Exchange in the Molten (Lithium Chloride-Potassium Chloride-Alkali Metal Chloride) Salt + Zeolite 4A System with Alkali Metal Chlorides of Sodium, Rubidium, and Cesium. Metallurgical and Materials Transactions B 2001; 32B: 429-435.

5. Simpson MF, and Gougar MLD. Two-Site Equilibrium Model for Ion Exchange between Monovalent Cations and Zeolite-A in a Molten Salt. Industrial \& Engineering Chemistry Research 2003; 42: 4208-4212.

6. Gougar MLD. Fission Product Ion Exchange Between Zeolite and a Molten Salt. Ph.D. Dissertation, PA: Pennsylvania State University; 2004. 
7. Phongikaroon S. and Simpson M. F. Equilibrium Model for Ion Exchange Between Multivalent Cations and Zeolite-A in a Molten Salt. AIChE Journal 2006; 52: 1736-1743.

8. Carnahan B, Luther HA, and Wilkes JO. Applied Numerical Methods. New York: Wiley, 1969, page 129.

\section{Task C2. Integrated fission product separations test with salt from Mark-IV electrorefiner}

A major task from the second phase (FY-08) of this I-NERI project was to downselect the most promising methods for fission product removal from ER salt. The two methods chosen as the most promising were rare-earth (and yttrium) fission product precipitation by oxygen bubbling, as proposed by KAERI, and salt/zeolite contacting as proposed by the INL.

In the case of oxygen bubbling, KAERI utilized lab-scale rare-earth (lanthanide elements) precipitation equipment with a 4-kg maximum batch size. Using this apparatus, precipitation experiments were carried out for multiple-rare earth system using nonradioactive elements as surrogates. This system contains 8 rare-earth elements ( $\mathrm{Y}, \mathrm{La}, \mathrm{Ce}$, $\mathrm{Pr}, \mathrm{Nd}, \mathrm{Sm}, \mathrm{Eu}$ and $\mathrm{Gd})$. Reaction with oxygen gas converts $\mathrm{Y}, \mathrm{La}, \mathrm{Pr}, \mathrm{Nd}, \mathrm{Sm}, \mathrm{Eu}$ and $\mathrm{Gd}$ to their oxychloride forms (REOCl), while Ce and Pr are converted to their oxide forms $\left(\mathrm{CeO}_{2}, \mathrm{PrOCl}\right)$. Since these rare-earth oxichlorides or oxides are not soluble in the molten salt, they were all precipitated by free settling. About $7 \mathrm{hrs}$ of precipitation time was required. It was found that in the conditions of $700^{\circ} \mathrm{C}$ salt temperature and 12 hours of oxygen sparging with a flowrate of $5 \mathrm{~L} / \mathrm{min}, 99.5 \%$ of the rare-earth elements were oxidized. In the case of $800{ }^{\circ} \mathrm{C}$ salt temperature, the oxidation efficiency was around $99 \%$ after only 6 hours of operation. Of these two salt temperature conditions, when considering the possibility of salt entrainment and material corrosion, $800^{\circ} \mathrm{C}$ salt temperature seems to be more favorable condition.

The method of salt/zeolite contacting is the current method of ER salt immobilization used in the spent fuel treatment of EBR-II fuel at the INL. The salt occluded zeolite is then treated to produce a ceramic waste form (CWF) for geologic disposal. With the EBR-II spent fuel treatment process, the CWF produced has only low levels of fission products loading. The salt/zeolite contacting process being investigated in this I-NERI project aims remove fission products directly from the ER salt, producing a high fission product loaded zeolite and allowing recycle of the ER salt. This would reduce processing operating cost and significantly decreases the total volume of waste generated during electrochemical treatment of the spent fuel. Several schemes have been proposed to efficiently load zeolite with fission products from ER salt, most notably by flowing molten salt through zeolite columns and then returning the decontaminated salt to the electrorefiner. A different approach was taken for the salt/zeolite contacting method proposed for this project; and that is to simply submerge zeolite into a bath of molten salt 
and allow the zeolite to saturate with fission products. The zeolite is then removed from the salt bath for waste processing. The goal here was not to achieve complete decontamination of the ER salt, only to reduce the concentration of fission products in the salt before reuse. To accomplish this, a steel mess basket containing zeolite in pellet form was submerged into the molten salt bath until ion exchange equilibrium had been obtained after which the basket is removed from the salt bath.

\section{C2.1 Equipment Mock-up and Surrogate Testing of Salt/Zeolite Contacting and Oxygen Sparging Equipment}

Prior to separation experiments of fission products from ER salt performed in the HFDA, equipment was fabricated and methods tested using surrogate ER salt in a nonradiological facility. Surrogate salt experiments were performed in an inert atmosphere glovebox in the Engineering Development Laboratory, Building 772 at the Materials and Fuels Complex (MFC) on the INL site. All salt handling and sample preparation for the oxygen precipitation and zeolite contacting experiments were conducted in this argon atmosphere glovebox (figure C2.1). Typical oxygen levels within the glovebox rang from 85 to 150 parts-per-million (ppm).

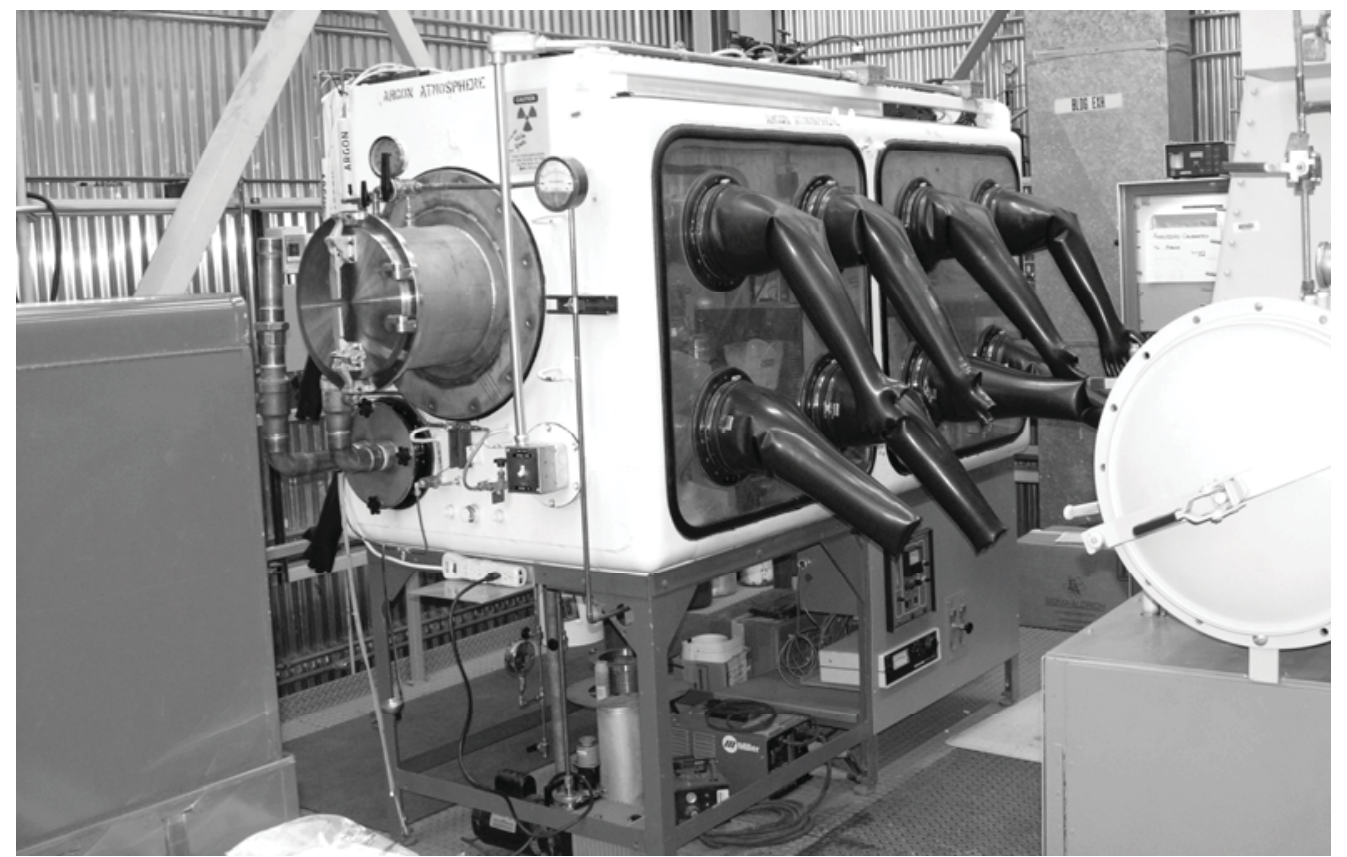

Figure C2.1.1 Engineering Development Laborotory, glovebox used to perform nonradioactive zeolite contacting and oxygen sparging experiments.

\section{C2.1.1 Surrogate Salt/Zeolite Contacting Experimental Methods}

Surrogate salt/zeolite contacting experiments had been conducted extensively for phase one and two (FY-07, -08) of the I-NERI project for the determination of ion exchange thermodynamic data. During these experiments, the zeolite pellets were contained in a steel basket while submerged in the molten salt. Removal of the solid, salt 
contacted zeolite from the basket after each experiment was difficult and required rinsing the basket with water to dissolve adhering salt from the zeolite. This operation is not practical for hot cell operations and an alternative method was attempted to ease sample handling in the HFEF facility. This involved the fabrication of monolithic zeolite using an inorganic binder. A description of the various aspects of the salt/zeolite experimental procedure is given below.

\section{Zeolite Drying}

Zeolite 4A used in experiments was dried to remove unwanted water occluded within its structure. The zeolite was dried in a furnace at $550^{\circ} \mathrm{C}$ for a minimum of 18 hours while under reduced atmospheric pressure of approximately $1 \times 10^{-3}$ torr. Zeolite moisture levels were tested after drying via Karl Fischer titration. The moisture levels were less than $0.5 \mathrm{wt} \%$.

\section{Monolithic Zeolite Fabrication}

Monolithic zeolite samples were prepared by mixing dried, $0.5 \mathrm{~mm}$ zeolite pellets with and inorganic binder. The binder, Ceramabind 642 (Aremco Products, Inc, Valley Cottage, NY, USA) is an inorganic binder comprised of silicate solution of a proprietary protected formulation. The zeolite pellets were mixed with the liquid binder in proportions of $2: 1$ by weight, then cured at $95^{\circ} \mathrm{C}$ for 1 hour and then at $150^{\circ} \mathrm{C}$ for 2 hours. A tungsten wire was partially submerged into the mixture, with the end extending from the monolith to act as a grappling attachment. For most experiments, the mass of zeolite pellets used was approximately 3 grams and yielded monolith from 2 to $3 \mathrm{~cm}^{3}$. Figure C2.1.1.1 shows the zeolite and binder with grappling wire.
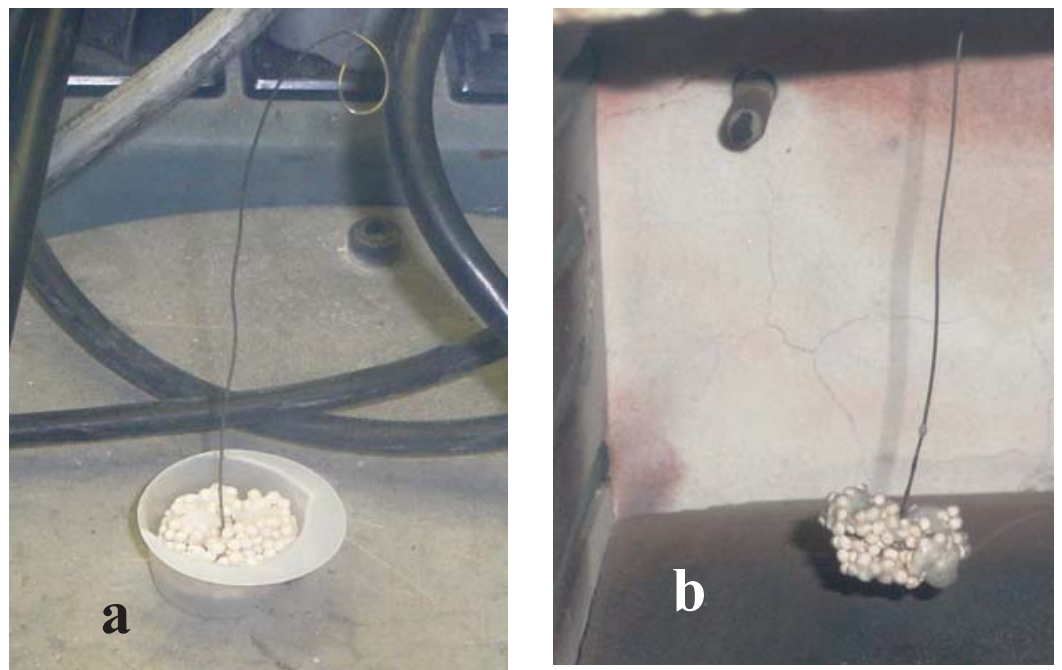

Figure C2.1.1.1. a) Zeolite mixed with Ceramabind inorganic binder with grappling wire prior to curing. b). Zeolite monolith after curing in furnace.

\section{$\underline{\text { Surrogate Salt/Zeolite Contacting Experiments }}$}


The method used for salt/zeolite contact experiments first involved preparing quaternary eutectic salt compositions by mixing the $\mathrm{LiCl}-\mathrm{KCl}$ eutectic salt with the individual surrogate chloride salts. The surrogate fission product salts used were ultradry, high-purity $\mathrm{CsCl}$ and $\mathrm{NdCl}_{3}$ (Alfa Aesar, Ward Hill, MA, USA). Individual salt mixtures were then transferred to a steel beaker and placed in a furnace for melting and subsequent salt/zeolite contacting. The temperature of the salt bath in the furnace was monitored with a thermocouple inserted through the top of the furnace. When new salt mixtures were added to the furnace, the furnace temperature was ramped to $700^{\circ} \mathrm{C}$ to superheat the salt mixture and insure that all salt components had melted and the salt was homogenous. The furnace temperature was then reduced to $500^{\circ} \mathrm{C}$, the temperature at which the zeolite contacting experiments were conducted. The mole fraction concentrations of $\mathrm{CsCl}$ and $\mathrm{NdCl}_{3}$ in the eutectic were 0.03 each. The total mass of the salt was approximately $120 \mathrm{~g}$.

Prior to and after salt/zeolite contacting experiments, salt samples were obtained from the molten salt mixture and then analyzed to measure salt composition. Salt samples were extracted using a stainless steel tube lowered into the molten salt with a slight negative pressure applied to draw liquid salt into the tube. The tube was then removed from the bath and placed over a glass beaker, at which time the negative pressure released. The liquid salt then flowed from the sampling tube into the beaker, where the salt sample solidified. This method yielded approximately $2 \mathrm{~g}$ of salt. The salt was then dissolved in $2 \%$ vol nitric acid/de-mineralized water and diluted for elemental analysis by inductively coupled plasma-mass spectrometry (ICP-MS).

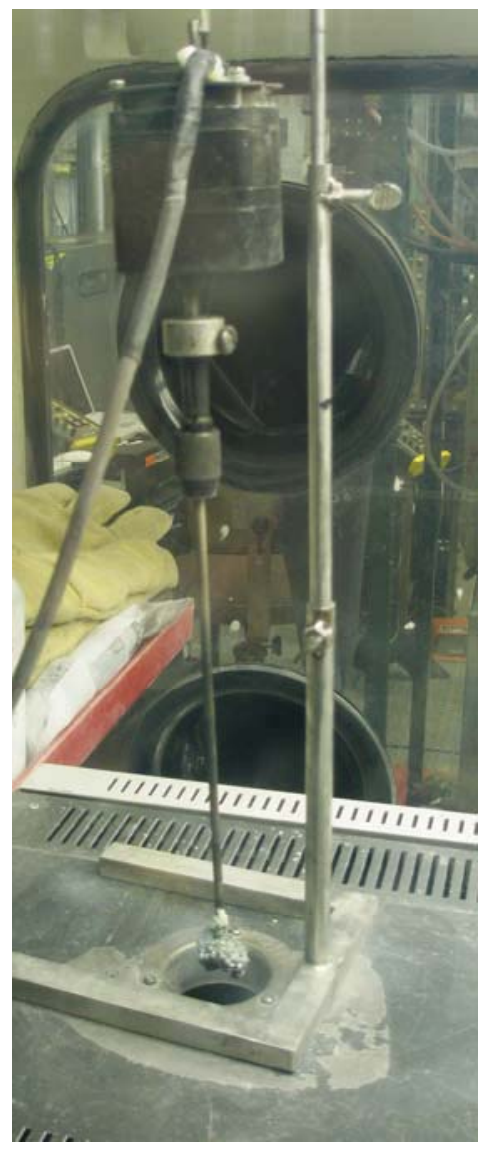

Salt/zeolite-contacting experiments were performed by attaching the grappling wire of the monolithic zeolite to a stirring rod and submerging the monolithic zeolite into the molten salt bath (figure $\mathrm{C} 2.1 .1 .2$ ). The stirring rod was attached to an electric motor suspended from an adjustable clamp stand that allowed the monolithic zeolite to be lowered or raised through the top of the furnace and into the salt bath. The electric motor rotated the zeolite during contacting experiments. All contacting experiments were conducted for a minimum of 24 hours at a temperature of $500^{\circ} \mathrm{C}$. At the conclusion of the contact period, the monolithic zeolite was raised above the salt level but still within the furnace and allowed to rotate for $\sim 1$ minute in an attempt remove excess salt from the zeolite. The monolithic zeolite was removed from the furnace cavity and allowed to cool. After the zeolite cooled, it was removed from the glovebox for subsequent digestion and elemental analysis. 
Figure C2.1.1.2. Apparatus used in zeolite contact experiments showing the monolithic zeolite suspended from stirrer above the furnace, after submersion into the molten salt.

\section{Elemental Analysis}

Procedure for Salt Sample Digestions:

Salt samples weights were determined with sample weights ranging between $0.1-$ 0.5 grams. These samples were then dissolved in acid solutions of 1 to 2 volume percent nitric acid (trace metal grade). These dissolver solutions were then further diluted as much a 1:10,000, depending on sample size, in $5 \% \mathrm{HNO}_{3}$ solution and measured for elemental composition using an Elan DRC-e ICP-MS (PerkinElmer, Shelton, CT, USA).

\section{Procedure for Zeolite Sample Digestions:}

Salt-contacted zeolite pellets were ground to a fine powder using a mortar and pestle. The powder was then washed using $\sim 30 \mathrm{~mL}$ of di-mineralized water and collected through vacuum filtration onto a filter paper. The powder was then dried and weighed. Typical sample weights ranged from 0.1 to 0.3 grams. The weighed powder was then added to a 100-mL Teflon beaker for dissolution.

Three milliliters of concentrated nitric acid and $3 \mathrm{~mL}$ of concentrated hydrochloric acid were added to the beaker and gently heated. Then $2 \mathrm{~mL}$ of concentrated hydrofluoric acid was added, and the solution heating was continued until all powder had dissolved. When dissolution was complete, $30 \mathrm{~mL}$ of a mixture containing $2.2 \%$ boric acid and $0.2 \%$ EDTA was added to the beaker, and the solution warmed again for $15-20$ minutes. The addition of the boric acid/EDTA solutions was performed to assure that any possible fluoride precipitates were dissolved back into solution. For dissolved zeolite solutions containing La, it was imperative to keep the dissolver solution at a high nitric acid concentration of $6 \mathrm{~N}$ or higher to keep La from precipitating out of solution. All precipitates should have dissolved at this point, and the solution should have appeared clear. If a precipitate remained, heating was continued. After heating, the solutions were cooled and then diluted with de-mineralized water to a total volume of approximately 60 $\mathrm{mL}$. The solutions were further diluted by a factor of 1000 using $5 \%$ nitric acid and submitted for ICP-MS analysis.

\section{Experimental Results}

Elemental analysis showed that monolithic zeolite bonded with Cerama-Bind 642 performed as well for the occlusion of electrolye cations as non-bonded zeolite used in the equilibrium studies. As illustrated in figure C2.1.1.3, the mole equivalent of surrogate fission products $\mathrm{Cs}$ and $\mathrm{Nd}$ show comparable or slightly better occlusion or ionexchange into the zeolite, respectively, than the non-bonded zeolite. 


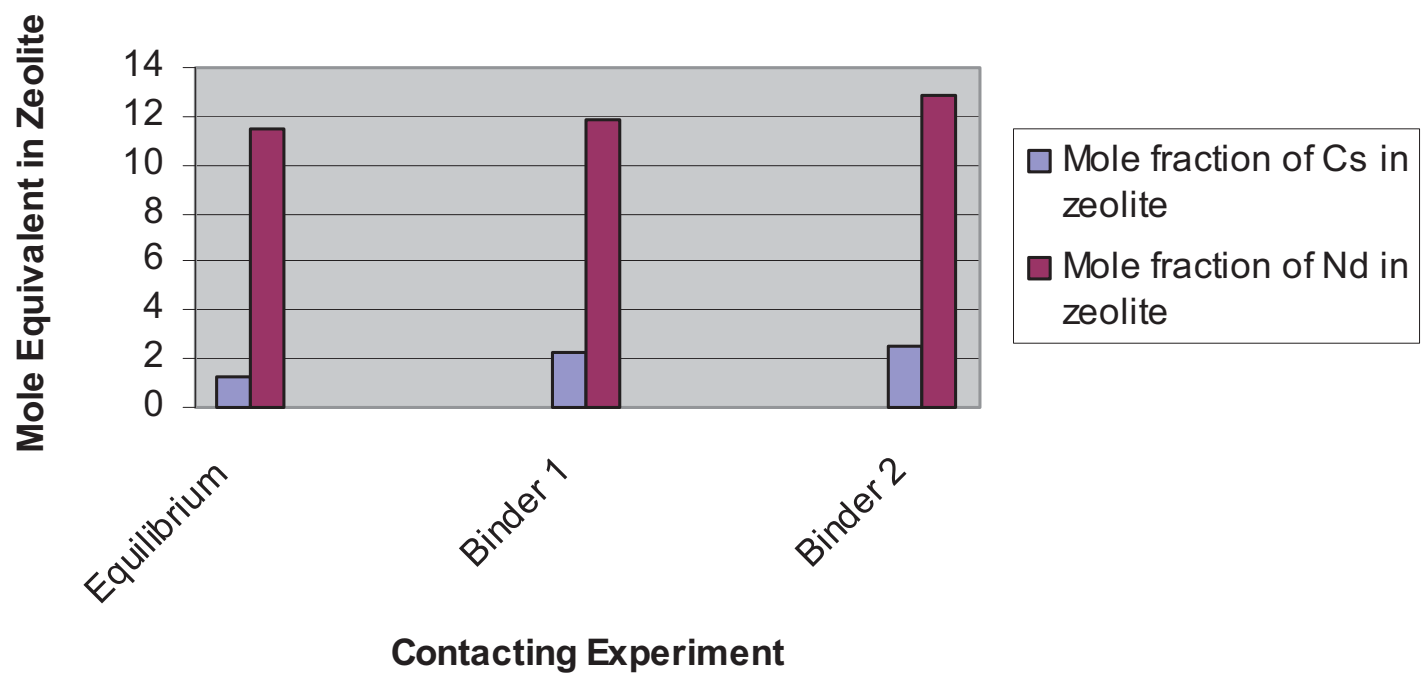

Figure C2.1.1.3. Mole equivalents of Cs and Nd in zeolite after contacting experiments using monolithic zeolite. The comparison is made of quaternary $\mathrm{Cs} / \mathrm{Nd}-\mathrm{LiCl}-\mathrm{KCl}$ salt mixtures used in the initiation equilibrium experiments and two monolithic zeolite samples with binder. The results indicated that the monolithic zeolite with binder performed as well or better than zeolite without binder.

Unfortunately, the monolithic zeolite proved to be only moderately durable and on occasion broke from the grappling wire as shown in figure C2.1.1.4. This lack of monolithic zeolite durability was counter to the original intent of producing solid zeolite for hot cell applications. With more effort toward zeolite/binder formulation, it is expected that a suitable monolithic zeolite material can be produced. However, from these initial tests it was concluded that the zeolite pellets would have to be enclosed in a steel basket similar to the baskets used in the equilibrium tests for HFEF applications. After salt contacting the zeolite would then have to be cut out of the basket in the HFEF hot cell. The steel basket fabricated for the salt/zeolite contacting experiment in the HFDA as shown in figure C2.1.1.5. 


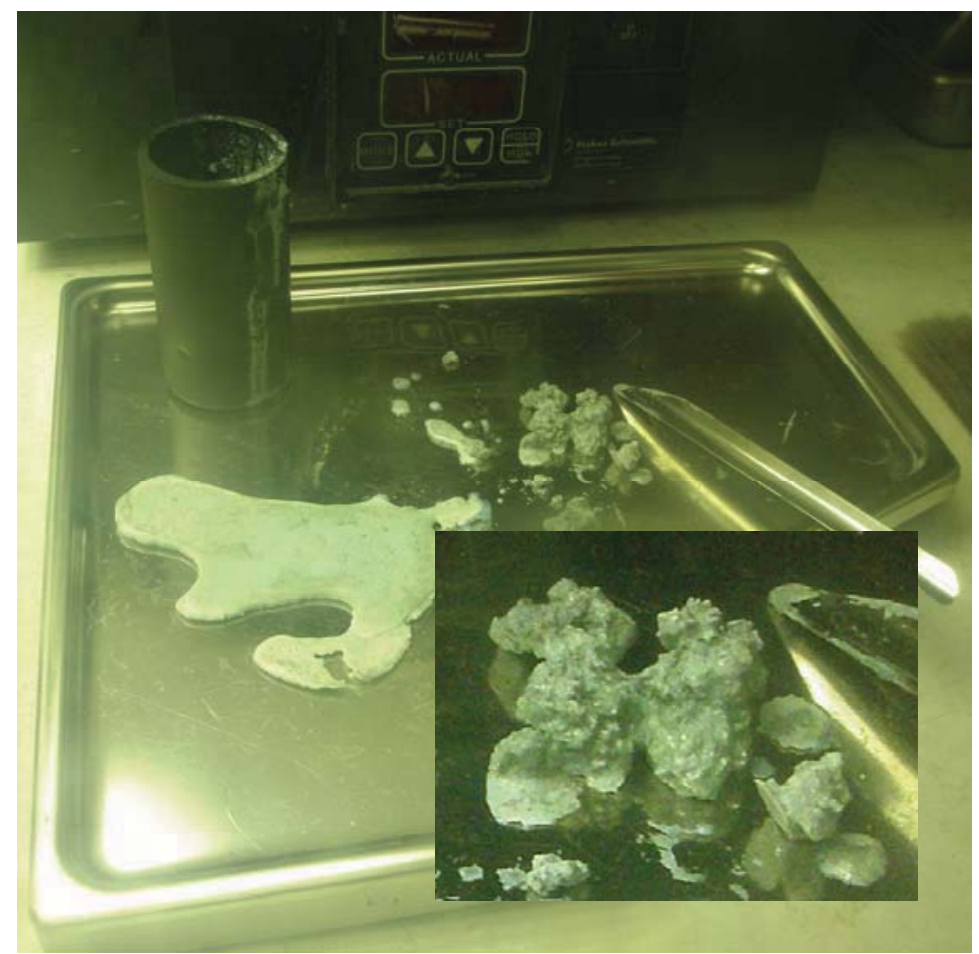

Figure C2.1.1.4. Broken zeolite monolith removed from molten salt bath. The monolithic zeolite had been bond using an inorganic binder and fixed to a grappling wire for submerging into the molten salt. The monolithic zeolite broke in the molten salt during the contacting experiment.

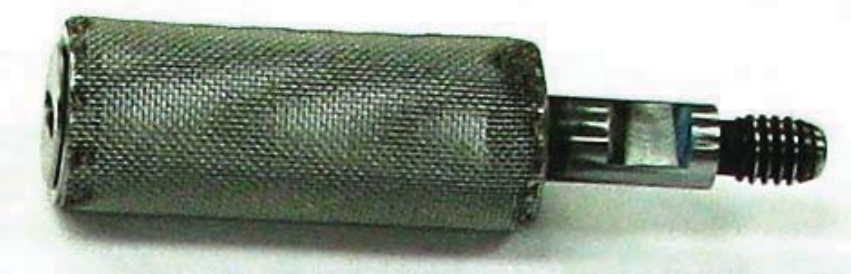

Figure C2.1.1.5. Steel basket fabricated for HFDA salt/zeolite contacting experiments.

\section{C2.1.2 Surrogate Fission-Product Precipitation with Oxygen Sparging Experimental Methods}

During phase 1 and 2 (FY-07 and FY-08) of this I-NERI project, KAERI developed methods of rare-earth fission product removal by chemical precipitation in $\mathrm{LiCl}-\mathrm{KCl}$ eutectic salt. Several chemical additives were investigated and oxygen gas bubbling (or sparging) in the molten salt was found to be effective in forming rare-earth (RE) oxide and $\mathrm{RE}$ oxychloride precipitates. These precipitates are insoluble in the molten salt and will settle to the bottom of the salt bath after formation. This was the second fission product separation method chosen for demonstration in the HFDA. As with the salt/zeolite 
contacting method, mock-up and testing of equipment and procedures for precipitation was performed in the glovebox in the Engineering Development Laboratory.

KAERI's extensive investigation of RE fission product precipitation by oxygen sparging yielded equipment and methods that were not easily adaptable for use in the HFDA. Modifications to equipment and methods were implemented and tested. The major modification of the KAERI design and methods for oxygen sparging were:

- Oxygen-sparger design

- Oxygen flow rate

- Molten salt-bath temperature.

\section{Modification to KAERI Oxygen Sparging Equipment and Methods}

The KAERI design of the oxygen sparger itself, a cross-type perforate sparger shown in figure C2.1.2.1 a, was the biggest challenge to adaption to the HFDA. Specifically, insertion of the KAERI sparger-type into the access ports in the HFDA head cover and removal from the salt bath would prove problematic. Similar work at the INL using porous metal-frit gas spargers had proven successful in similar applications, and a similar system was tested for molten-salt oxygen sparging. The system adapted for the HFDA is illustrated in figure C2.1.2.1b.
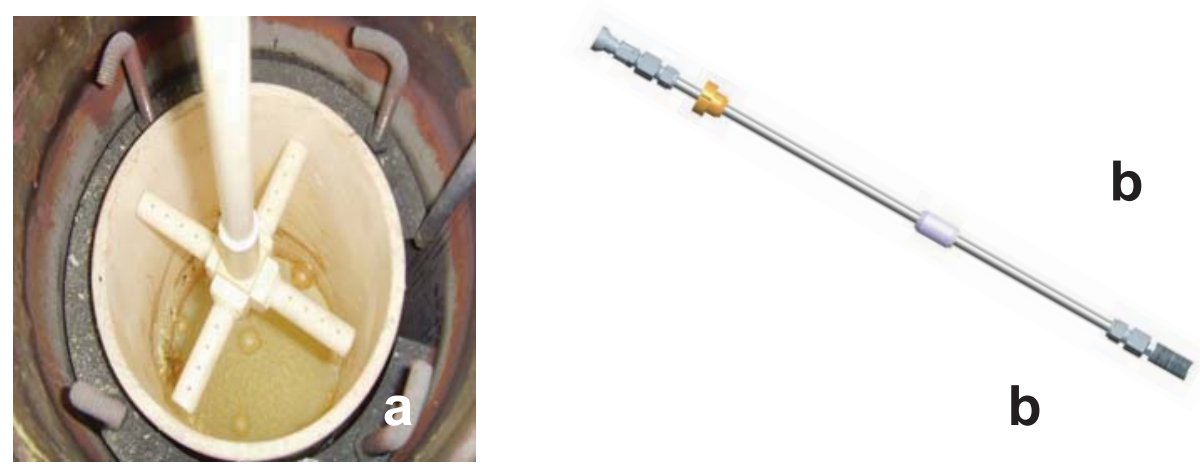

\section{Figure C2.1.2.1. a) KAERI cross-type sparger in molten-salt crucible. b) Porous metal-frit sparger and feedthrough rod designed for insertion in to the HFDA.}

For surrogate fission-product oxygen sparging, a precipitate collection tray was attached to the bottom of the metal-frit that allowed removal of collected precipitate from the molten salt after sparging. This metal-frit oxygen sparger/collection pan assembly is shown in figure C2.1.2.2. The dimensions of the metal-frit sparger are $1.3 \mathrm{~cm}$ in diameter and $2.5 \mathrm{~cm}$ long. The collection tray diameter was $5 \mathrm{~cm}$ at the top and just fit inside the steel crucible that contained the molten salt. The metal-frit sparger produced a vigorous flow of very small oxygen bubbles at low gas flow and low-head pressure. 
Metal-frit spargers were obtained from the Mott Corporation (Farmington, CT, USA) and were fabricated either from stainless steel or inconel 600.

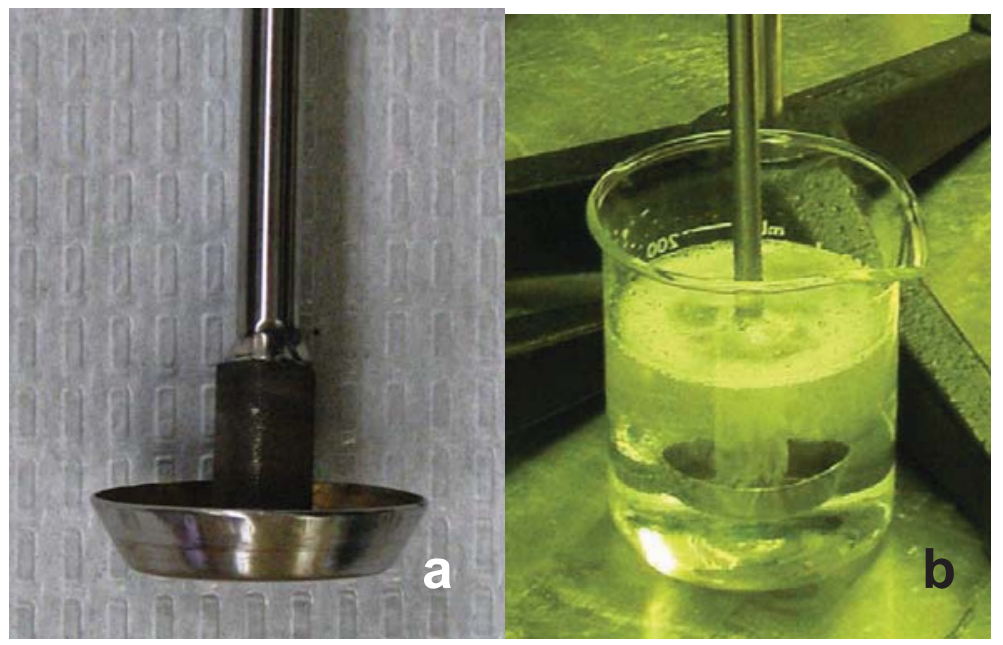

Figure C2.1.2.2. a) Surrogate salt oxygen sparger with collection tray assembly. b) Testing of metal-frit oxygen sparger in water before testing in molten salt.

The oxygen gas flow rate also had to be modified from optimal conditions determined at KAERI to what the HFEF facility would allow in the main hot cell where the HFDA is located. KAERI used high oxygen flow rates of $5 \mathrm{~L} / \mathrm{min}$ during oxygen sparging, however, the maximum allowable oxygen flow rate into the HFEF main hot cell is only $1 \mathrm{~L} / \mathrm{min}$ for a maximum of $60 \mathrm{~L}$ in a 24 hour period. From these administrative restrictions it was determined that a flow-rate of only $100 \mathrm{cc} / \mathrm{min}$ in an 8 hour period would be permitted. Therefore, all oxygen flow-rate tests were performed at $100 \mathrm{cc} / \mathrm{min}$.

The last modification to the KAERI oxygen sparge method was the temperature of the molten salt bath during precipitation. KAERI found optimum rare-earth precipitation formation at a temperature of $800^{\circ} \mathrm{C}$. The nominal operating temperature of the HFDA is $500^{\circ} \mathrm{C}$ and this limited what temperature could be obtained during oxygen sparging experiments in the HFDA. Therefore, all test sparging experiments were also performed at $500^{\circ} \mathrm{C}$.

\section{Surrogate Fission-Product Oxygen Sparging Experiments}

Oxygen sparging tests were performed in a similar manner to the salt/zeolite contacting experiments as described above. Quaternary salt mixtures of LiCl-KCl, with added quantities of 0.03 mole fraction $\mathrm{Nd}$ and $\mathrm{Cs}$ chlorides each, were prepared in the inert atmosphere glovebox where the experiments were also performed. The salt was added to a steel crucible and placed in the furnace for mixing at a temperature of $700^{\circ} \mathrm{C}$. After salt homogenization, the temperature of the furnace was reduced to $500^{\circ} \mathrm{C}$ and the metal-frit spager/collection tray assembly was placed into the molten salt bath. The oxygen flow to the sparger was initiated prior to insertion into the salt bath with a flow 
rate of approximately $100 \mathrm{cc} / \mathrm{min}$. This oxygen flow rate was maintained for a total of 8 hours with roughly $48 \mathrm{~L}$ of oxygen sparged into the molten salt bath.

After oxygen sparging, the gas flow was stopped and the precipitate allowed to settle into the collection pan over night while the salt bath remained at temperature. After the precipitation settling period, the sparging/collection pan assembly was carefully removed from the molten salt to recover the RE precipitate. Figure C2.1.2.3 shows the sparger/collection pan assembly prior to insertion into the furnace and the collected salt/precipitate product after oxygen sparging.
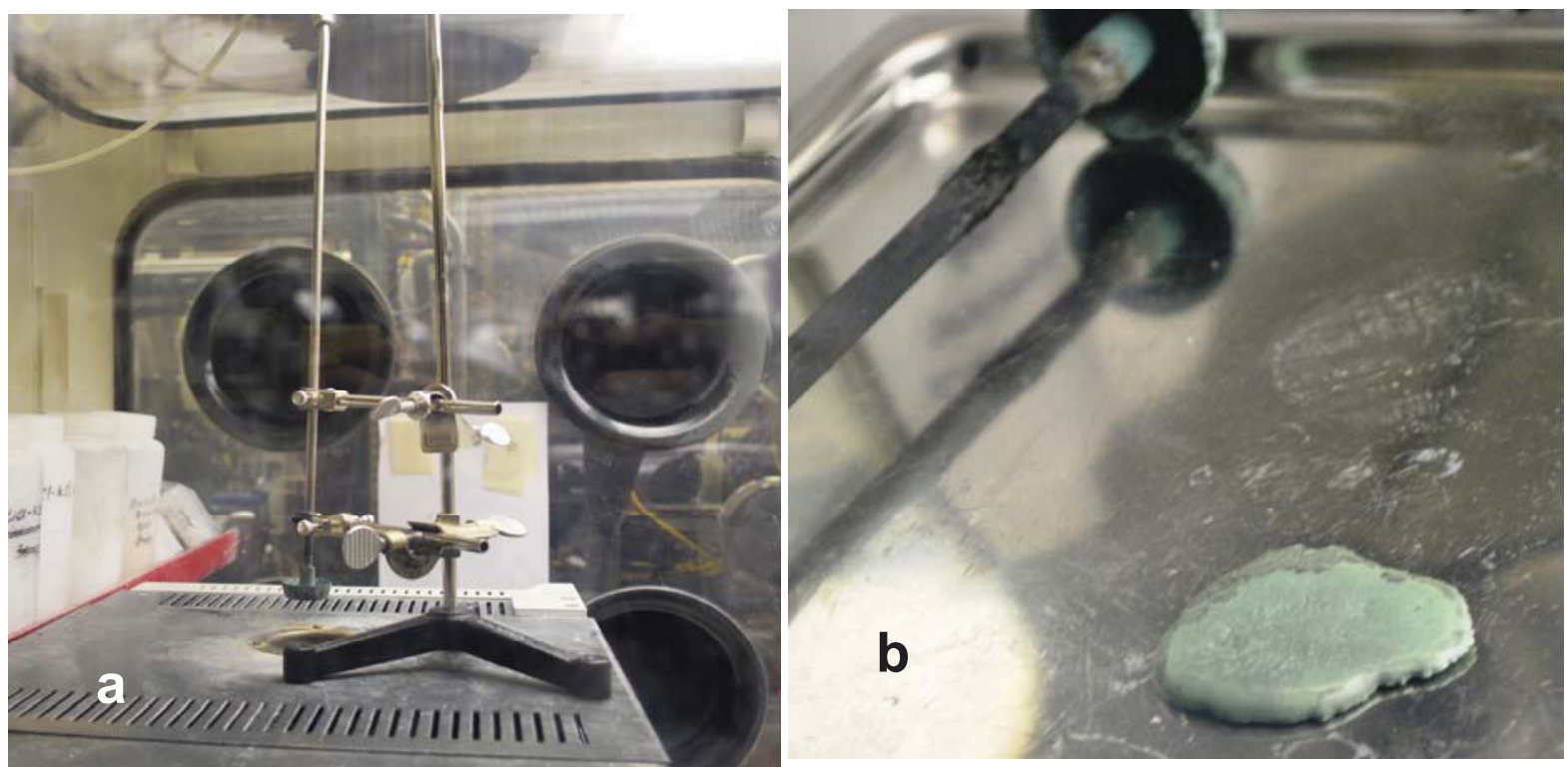

Figure C2.1.2.3. a) Metal-frit oxygen sparger/collection pan assembly prior to insertion into furnace and molten salt bath. b) Collected salt and surrogate fissionproduct precipitate after oxygen sparging experiment.

Salt samples were collected before and after each sparging experiment, using the sampling tube method, and then analyzed to determine changes to the salt composition with each experiment. The surrogate RE fission-product, in this case neodymium, was also isolated. This was performed by dissolving the salt containing the precipitate in a dilute acidic solution ( $1 \%$ vol nitric acid in dematerialized water) and collecting the precipitate on filter paper after vacuum filtration. X-ray diffraction was then performed on the filtrate and the precipitate identified as $\mathrm{NdOCl}$ as shown in figures C2.1.2.4 and C2.1.2.5. 


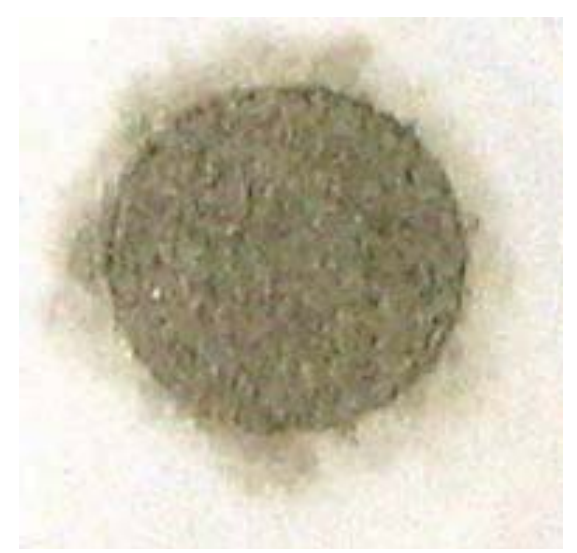

Figure C2.1.2.4. Neodymium precipitate collected after surrogate oxygen sparging experiment.

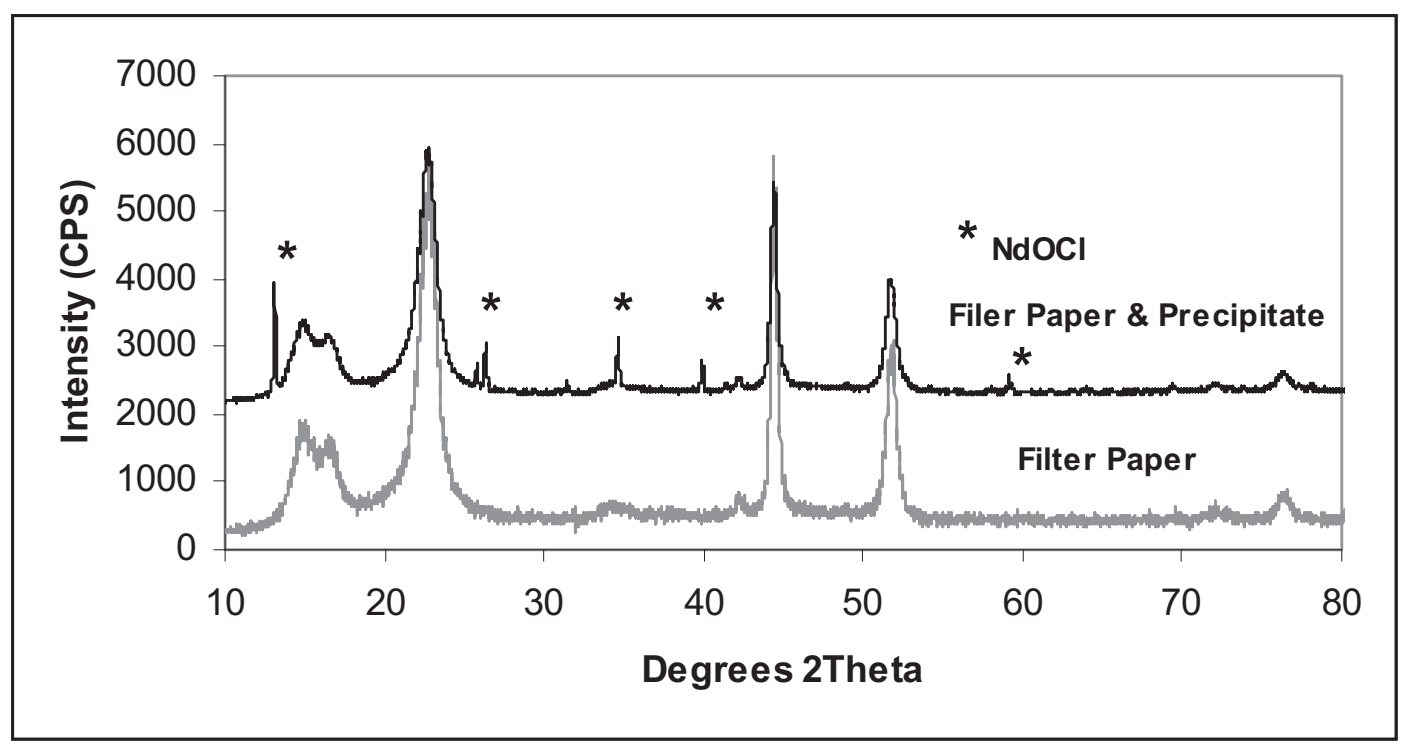

Figure C2.1.2.4. X-ray diffraction pattern of neodymium precipitate collected on filter paper. The precipitate was identified as the oxychloride NdOCl.

Estimation of $\mathrm{Nd}$ recovery from the surrogate salt as the precipitate was performed by determining the weight of the isolated precipitate and comparing this weight to the quantity of $\mathrm{Nd}$ in the salt before sparging. From this, the estimated recovery of $\mathrm{Nd}$ as the precipitate was $60 \%$ by weight from the total $\mathrm{Nd}$ in the salt.

The results for fission-product precipitation by oxygen sparging in the molten salt using the modified equipment and methods were deemed successful, and it was decided to proceed with experiments in the HFDA. However, subsequent oxygen sparging tests using surrogate salt in the Engineering Laboratory were less successful. Several more tests were attempted, but the metal-frit sparger clogged on a number of occasions and stopped the flow of oxygen into the molten salt. This caused significant concern for the success of the tests to be performed in the HFDA using the porous metal-frit spargers. 


\section{C2.1.3 Fission-Product Precipitation by Oxygen Sparging Using Mark IV Electrorefiner Salt in the HFDA}

Experiments to complete task C2 of the I-NERI project then proceeded to the Hot Fuels Dissolution Apparatus in HFEF. The salt used in the demonstration had originally had come from the Mark IV electrorefiner. The demonstration experiments were performed sequentially starting with salt/zeolite contacting and followed by the oxygen sparging. A salt sample was collected initially, and more salt samples collected after each experiment. The products from each demonstration were collected and stored for future use.

\section{Hot Fuel Dissolution Apparatus (HFDA)}

The HFDA is located at window 9M in the HFEF main hot cell (figure C2.1.3.1). The HFDA consists of two main components, the base assembly, and the head assembly. The base assembly contains the heaters and the molten salt crucible. The head assembly is remotely removable from the base, and contains the access ports, the heat shield baffles, and equipment to hold and rotate experiments in the molten salt.
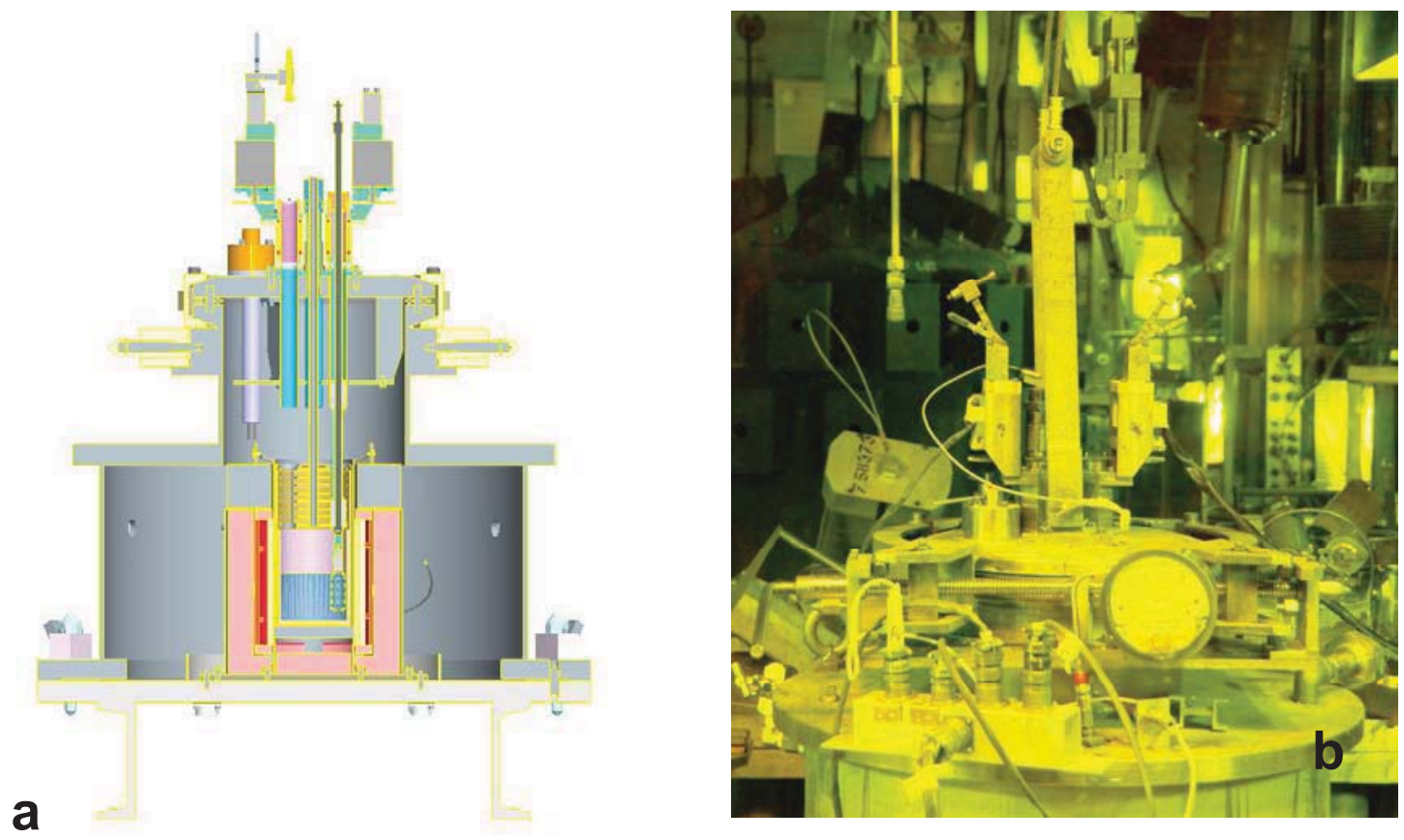

Figure C2.1.3.1. a) Cut-away drawing of the HFDA showing the heaters, heat shields and salt crucible of the base and, on top, the removable head unit with feedthroughs. b) HFDA in HFEF main cell showing head unit.

\section{$\underline{\text { Fabricated Equipment }}$}

No modification to the HFDA itself was required to perform the salt/zeolite contacting or oxygen sparging experiments. Only slight modifications were required to the standard HFDA insertion feedthroughs to hold the zeolite basket or oxygen sparger. The 
fabricated basked to contain the zeolite pellets used for the contacting experiment is shown in figure C2.1.3.2; and the oxygen sparging assembly and the precipitation collection pan used for fission-product precipitation experiments is shown in figure C2.1.3.3.

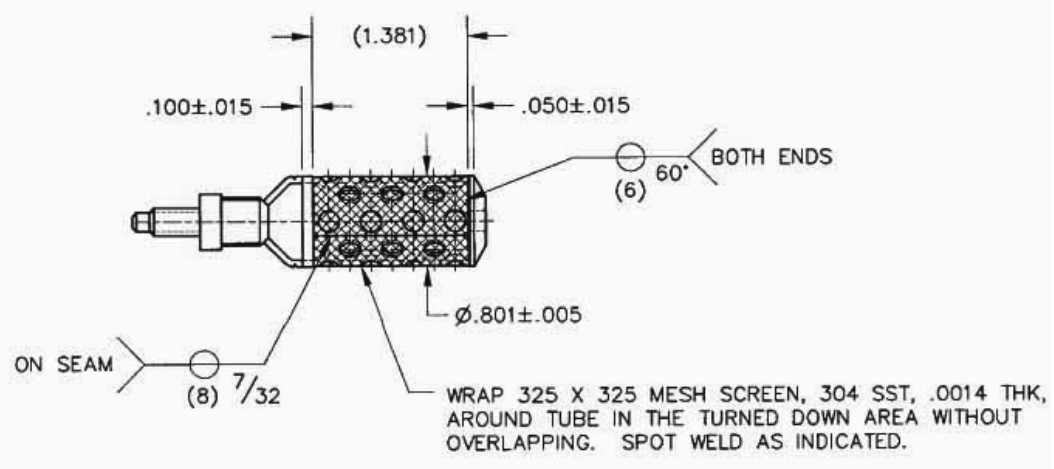

Figure C2.1.3.2. Design drawing of the zeolite basked used for HFDA salt/zeolite contacting experiments.
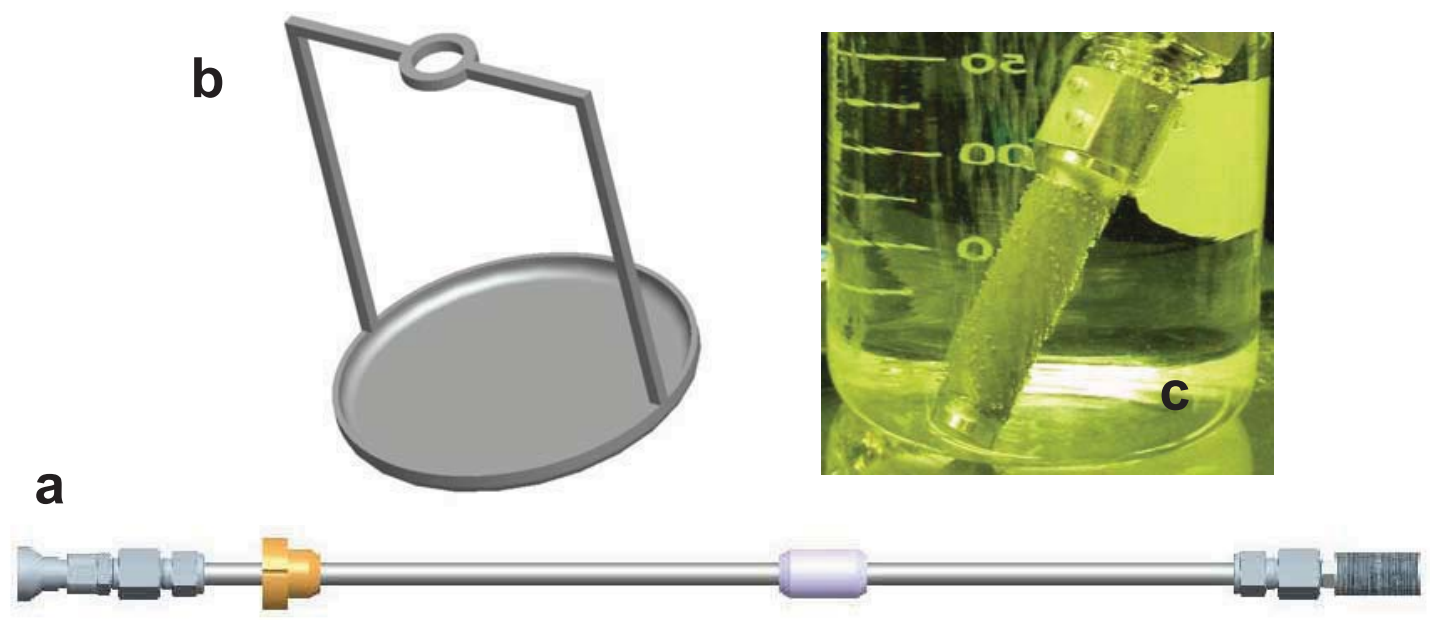

Figure C2.1.3.3. a) Autocad design drawing of the HFDA oxygen sparger and insertion rod/oxygen supply assembly, b) the precipitate collection pan, and c) the oxygen sparger being tested in water.

Both the zeolite basket and the metal-frit oxygen sparger were designed to be mounted onto a standard HFDA feedthrough rod assembly that can be lowered through one of the four feedthrough ports on the head of the HFDA. The precipitation collection pan was transferred into and out of the HFDA molten salt crucible while the HFDA head was removed.

\section{High Loaded Mark-IV Electrorefiner Salt}

The electrolyte used in both the salt/zeolite contacting and oxygen sparging demonstration experiments was a composite material that consisted of 758 grams of salt 
condensate retrieved from a cathode processor $(\mathrm{CP})$. The CP's primary function is to separate the adhering salt from the uranium dendrites produced by the Mark-IV and Mark-V electrorefiners through a high-temperature vacuum-distillation process that discharges the salt as a composite condensate and the dendrites as a consolidated metal ingot. The 758 grams of the condensate salt used in this demonstration contained sodium, actinides, and fission products from processing spent driver fuels from EBR-II. Rareearth chlorides, such as $\mathrm{NdCl}_{3}, \mathrm{CeCl}_{3}, \mathrm{LaCl}_{3}, \mathrm{PrCl}_{3}, \mathrm{SmCl}_{3}$, and $\mathrm{YCl}_{3}$, were purposely added to the salt to produced the high-loaded material. The composition of the initial, high-loaded electrorefiner salt was:

- LiCl-KCl: $88.8 \mathrm{wt} \%$

- Alkali elements ( $\mathrm{Na}, \mathrm{Rb}, \mathrm{Cs}): 1.6 \mathrm{wt} \%$

- Alkaline earth elements (Sr, Ba): 0.8 wt\%

- Lanthanides (La, Ce, Pr, Nd, Sm) and Y: 5.5 wt\%

- Actinides (U, Np, Pu Am): 3.3 wt $\%$

\section{$\underline{\text { HFDA Salt/Zeolite Contacting Demonstration Experiment }}$}

Before salt/zeolite contacting, an approximately $2 \mathrm{~g}$ salt sample was obtained from the HFDA molten salt bath using a sampling rod. This sample was then pneumatically transferred to the Analytical Laboratory (AL) hot cells at MFC for elemental analysis. $8.8 \mathrm{~g}$ of dried zeolite was added to the zeolite basket and submerged into the HFDA salt bath. The temperature of the salt bath was $500^{\circ} \mathrm{C}$ and the zeolite basket remained in the salt bath for 24 hours while being rotated. After the 24 hour contacting period, the basket assembly was removed from the bath and allowed to cool. The bottom end of the basket was cut off and the zeolite with adhering salt crushed out of the basket. A salt sample was collected for analysis and the collected salt contacted zeolite was stored for future use. The basket and recovered salt covered zeolite is shown in figure C2.1.3.4. 

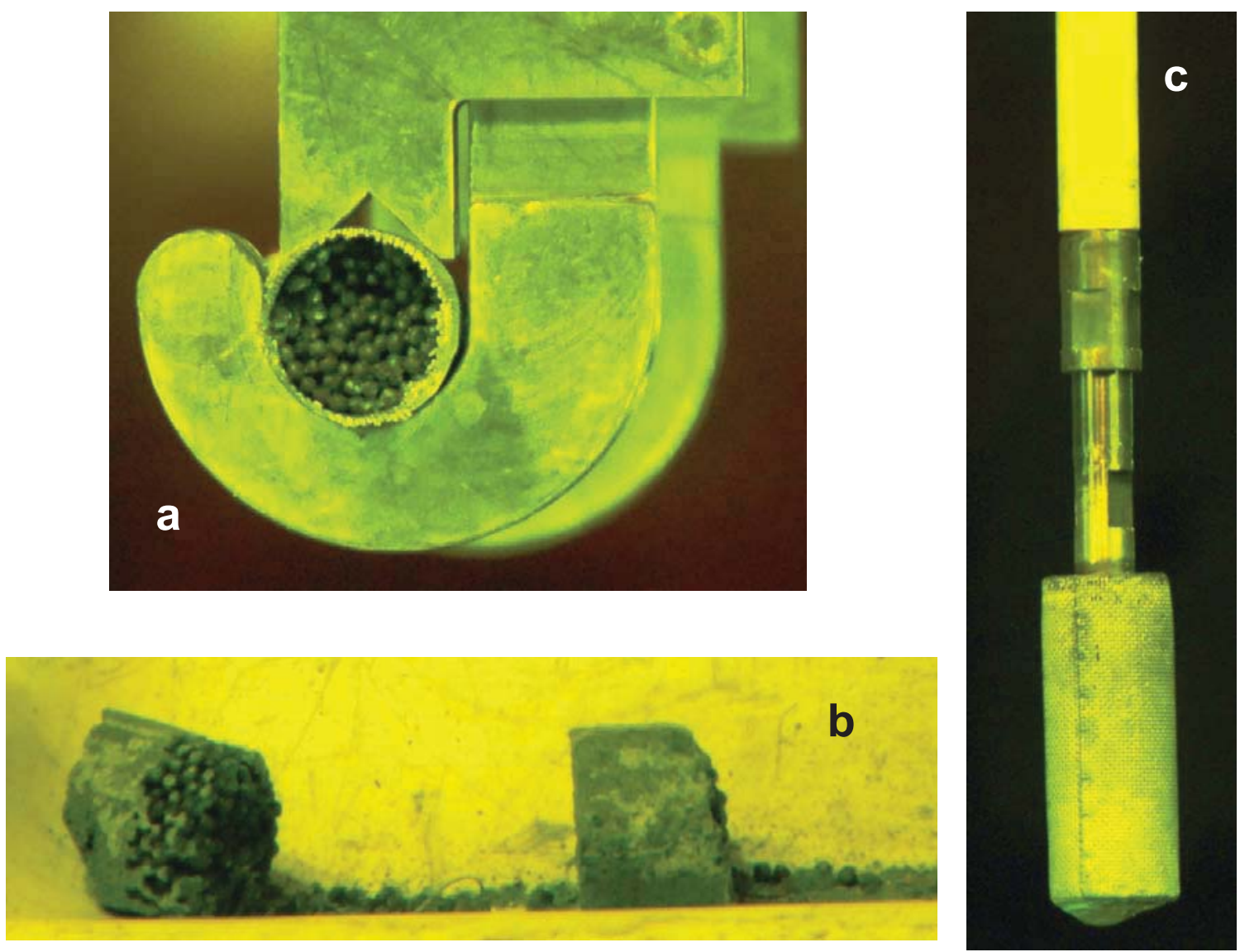

Figure C2.1.3.4. a) Cut zeolite basket showing salt coated zeolite pellets after salt/zeolite contacting in the HFDA, b) collected salt contacted zeolite, and c) zeolite basket after removal from salt bath in the HFDA.

\section{HFDA Fission-Product Precipitation by Oxygen Sparging Demonstration Experiment}

After completion of the salt/zeolite contacting demonstration, the HFDF cover lid was removed and the precipitation collection pan placed in the salt bath. The cover lid was then placed back on the HFDA and a salt sample collected. An oxygen flow rate of $120 \mathrm{cc} / \mathrm{min}$ was applied to the oxygen sparging apparatus and the sparger inserted through a penetration in the head of the HFDA and into the salt bath. The temperature of the salt bath was maintained at $500^{\circ} \mathrm{C}$.

Originally, it was assumed that sparging would be performed for only 8 hours in a 24-hour period to prevent exceeding the $\mathrm{O}_{2}$ hot-cell limit, and then resuming sparging for another 8 hours until a total of 24 hours of sparging time had been completed. However, oxygen monitors in the main cell never recorded an increase in $\mathrm{O}_{2}$ levels (HFEF main cell $\mathrm{O}_{2}$ levels usually average $\sim 50$ to 100 parts per million). Therefore, facility permission was granted to continue oxygen sparging continuously for 24 hours with a total of $173 \mathrm{~L} \mathrm{O}_{2}$ bubbled into the HFDA salt. The oxygen flow rate remained constant for the 24-hour sparging period indicating that no clogging of the sparger occurred. 
After 24 hours of continuous oxygen bubbling, the sparger apparatus was removed from the HFDA and the precipitate allowed to settle for another 24 hours into the collection pan while the HFDA remained at temperature. After precipitate settling, the head to the HFDA was removed and the collection pan slowly removed from the molten salt, allowed to cool, and the final salt sample was collected for analysis. After the salt/precipitate from the collection pan had cooled, it was broken out of the pan and stored for future use. The oxygen sparger assembly and collection pan with salt/precipitate product is shown in figure C2.1.3.5.
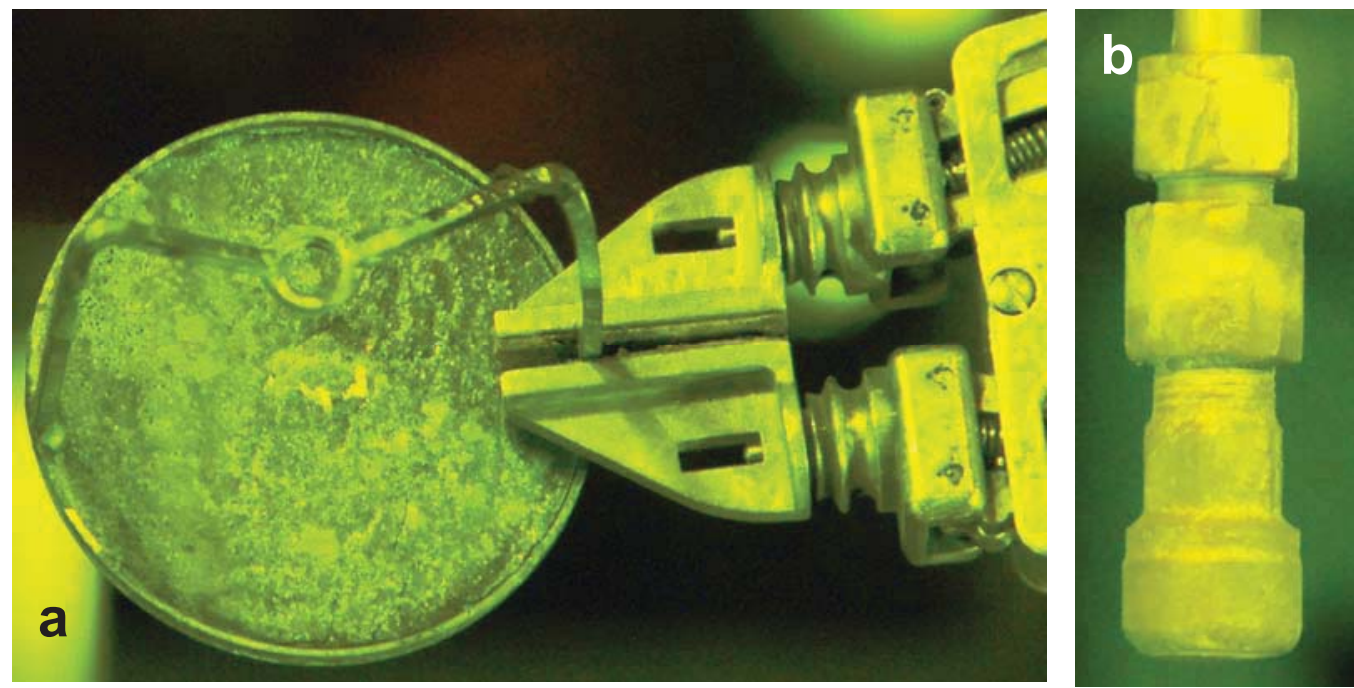

Figure C2.1.3.5. a) Collection pan with salt/precipitate product after oxygen sparging in HFDA, b) Oxygen sparger assembly after 24 hour sparging in HFDA the oxygen flow remained constant during the sparging experiment indicating that no clogging of the sparger occurred.

\section{$\underline{\text { Results of Elemental Analysis of HFDA Salt Samples }}$}

Three HFDA salt samples were collected (pre-test salt sample, post-salt/zeolite contacting salt sample, and post-oxygen sparging salt sample) and pneumatically transferred to the AL hot cells. These samples were then weighted and dissolved. The dissolution involved placing the salt samples in a slightly acidic solution, then increasing the solution acidity to a final $6 \mathrm{~N}$ nitric acid concentration. No undissolved material was observed during dissolution. The dissolver solutions were then diluted and elemental analysis performed by ICP-atomic emission spectroscopy and ICP-MS. Results from these analyses are shown in table C2.1.3.1 and figures C2.1.3.6 and .7. 
Table C2.1.3.1. Difference in Elemental Composition of HFDA Mark-IV ER Salt after Salt/Zeolite Contacting and Precipitation by Oxygen Sparging. Analytical Uncertainty for each measurement is typically $\pm 5 \%$ RSD (negative \% values indicate and increase in elemental concentration).

\begin{tabular}{|c|c|c|}
\hline $\begin{array}{c}\text { Difference in Elemental } \\
\text { Concentration }\end{array}$ & $\begin{array}{l}\text { Salt/Zeolite } \\
\text { Contacting }\end{array}$ & $\begin{array}{c}\text { Oxygen } \\
\text { Precipitation }\end{array}$ \\
\hline \multicolumn{3}{|c|}{ Alkali and Alkaline Earth } \\
\hline $\mathbf{N a}$ & $-14.7 \%$ & $2.8 \%$ \\
\hline Rb & $0.6 \%$ & $2.6 \%$ \\
\hline Cs & $-0.4 \%$ & $0.7 \%$ \\
\hline $\mathbf{S r}$ & $-1.5 \%$ & $1.5 \%$ \\
\hline $\mathbf{B a}$ & $-1.5 \%$ & $1.7 \%$ \\
\hline \multicolumn{3}{|c|}{ Lanthanides (and Y) } \\
\hline $\mathbf{Y}$ & $10.6 \%$ & $5.2 \%$ \\
\hline La & $8.7 \%$ & $1.7 \%$ \\
\hline $\mathrm{Ce}$ & $8.3 \%$ & $0.0 \%$ \\
\hline $\mathbf{P r}$ & $7.0 \%$ & $-0.4 \%$ \\
\hline Nd & $9.4 \%$ & $-0.5 \%$ \\
\hline Sm & $5.8 \%$ & $1.0 \%$ \\
\hline \multicolumn{3}{|c|}{ Actinides } \\
\hline $\mathbf{U}$ & $35.0 \%$ & $36.5 \%$ \\
\hline $\mathbf{N p}$ & $13.1 \%$ & $-3.6 \%$ \\
\hline $\mathbf{P u}$ & $7.2 \%$ & $-4.1 \%$ \\
\hline
\end{tabular}




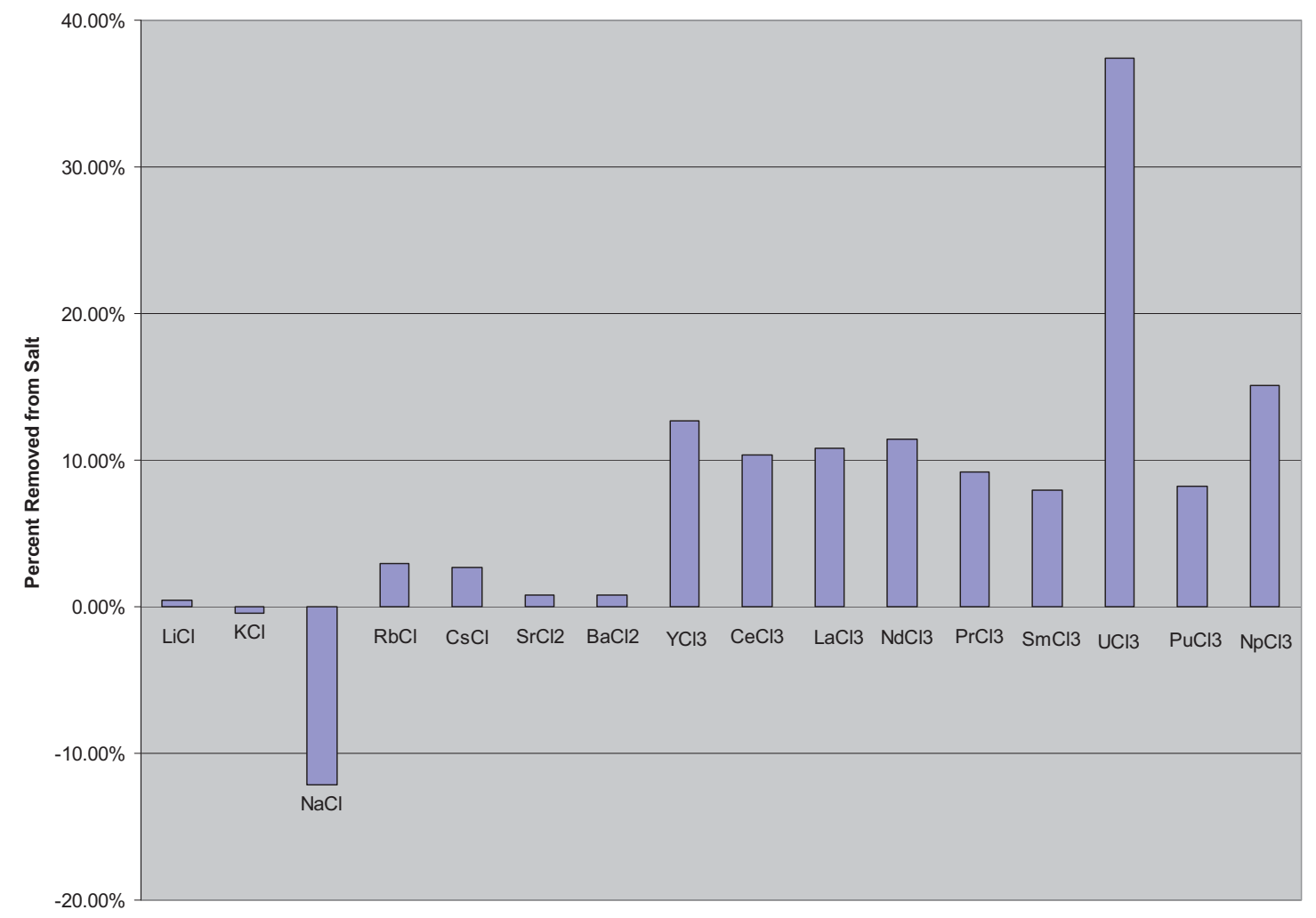

Figure C2.1.3.6. Difference in Elemental Composition of HFDA Mark-IV ER Salt After Salt/Zeolite Contacting. 


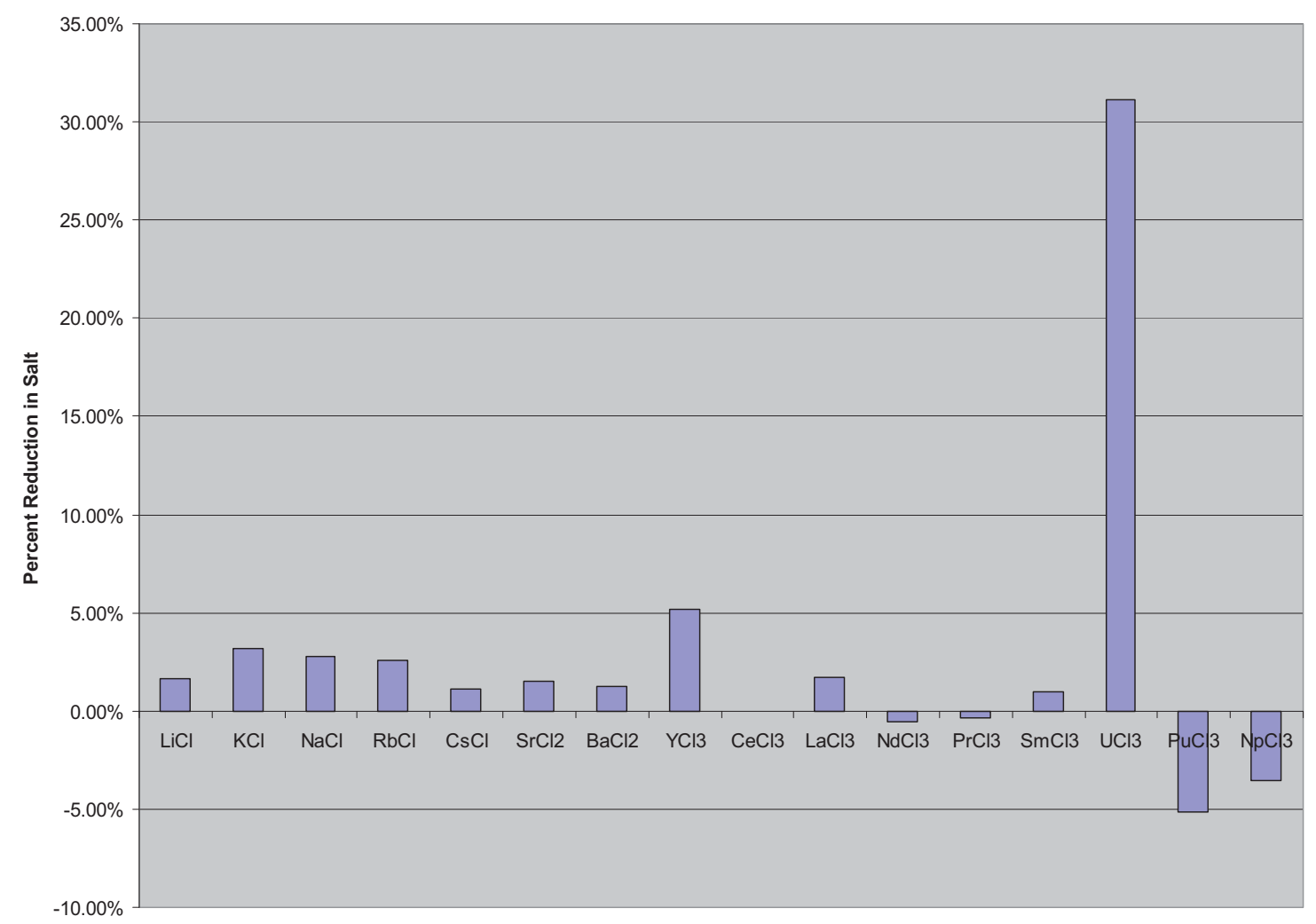

Figure C2.1.3.7. Difference in Elemental Composition of HFDA Mark-IV ER Salt After Precipitation by Oxygen Sparging.

The typical measurement uncertainty for the elemental analyses of the HFDA salt samples in $\pm 5 \%$ relative standard deviation (RSD). Therefore, for values listed in Table C2.1.3.1 and shown in figures C2.1.3.6 and C2.1.3.7 that are below the measurement uncertainty value are probably not significant. Values that are negative in the tables and figures indicate an increase of elemental concentration. Fission product removal for the HFDA salt/zeolite contacting experiment was significant, while fission product removal by oxygen sparging was less significant. The exception was in the case of uranium removal from the salt that was over $30 \%$ for both zeolite contacting and oxygen sparging.

Due to the limitations of the equipment used, facility restrictions, and ER salt composition, the removal of rare-earth fission products by oxygen sparging during the demonstration in HFEF from the salt were less than fission product removal obtained when the process is performed under optimum conditions. The causes for the less than expected rare-earth removal are:

1) Low operating temperature of HFDA - the maximum operating temperature of the HFDA is only $600^{\circ} \mathrm{C}$, well below the optimum precipitation temperature of $800^{\circ} \mathrm{C}$.

2) Low oxygen flow rate of $0.12 \mathrm{~L} / \mathrm{min}$ due to facility restrictions on $\mathrm{O}_{2}$ quantities allowed into the HFEF main hot cell - the optimum precipitation oxygen flow rate is 4 to $6 \mathrm{~L} / \mathrm{min}$. 
The high actinide content of the ER salt used in the precipitation demonstration - under expected rare-earth fission product separation operations, the ER salt would first undergo actinide draw-down so that the actinide content of the salt would be very low (below $0.1 \mathrm{wt} \%$ ). It is postulated that the high actinide content of the salt during the demonstration interfered with rare-earth oxide/oxychloride formation.

It must be stressed that the purpose of the HFDA separation demonstration experiments were not to judge the effectiveness of each method that had already been determined in the laboratory, but to demonstrate the applicability of each method to hot cell operations. By this criterion, each separation demonstration was successful. The next step is to perform each separation procedure under optimized hot cell conditions; unfortunately, that was beyond the ability of this demonstration.

\section{Task A3.2 Update. Comparision of HFDA Experiment to Salt/Zeolite Equilibrium Ion Exchange Model}

\section{A3.2.1 Equilibrium Model Background}

In the first two years of this project, an equilibrium model was developed for multi-component ion exchange between a molten salt and zeolite-A. This model assumed that there are two distinctly different types of sites for ion exchange in the zeolite- lattice sites and occlusion sites. The former involves ionic bonding to the zeolite framework - cations balancing negative charges in the zeolite. The latter involves space filling in the zeolite pores by whole chloride molecules. See Figure A3.2.1 for a graphical depiction of this physical model.

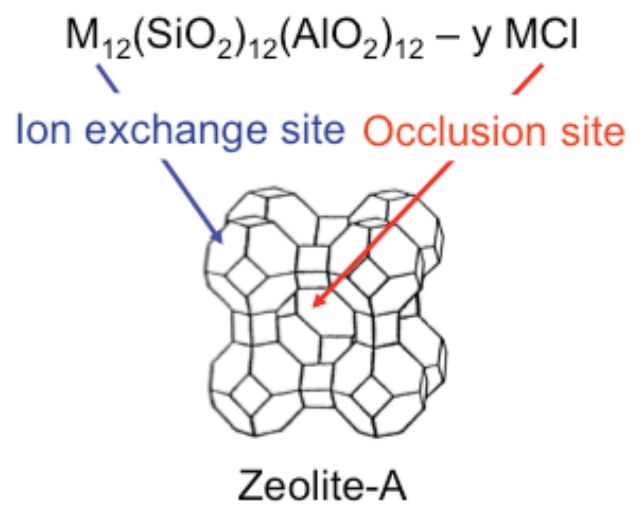

Figure A3.2.1. Proposed sites for ion exchange in zeolite-A

Based on the pseudo unit cell formula $\mathrm{M}_{12}\left(\mathrm{SiO}_{2}\right)_{12}\left(\mathrm{AlO}_{2}\right)_{12}, 12$ mole equivalents of cations are always loaded into the framework sites. In the as-synthesized zeolite, this is typically all $\mathrm{Na}^{+}$. As a result of immersion in the salt and equilibration, the $\mathrm{Na}^{+}$ions are replaced with $\mathrm{Li}^{+}, \mathrm{K}^{+}$, and the full spectrum of fission product cations. The number 
of occluded salt molecules per pseudo unit cell is typically 10 to 12 , depending on the composition of the salt and size of the chloride molecules being occluded. Details for the model can be found in a paper by Yoo et al. [ref. 1]. Model parameters that were determined from fitting surrogate salt data are given in Table A3.2.11.

Table A3.2.1. Equilibrium Model Parameters Determined from Surrogate Salt Fitting.

\begin{tabular}{|c|c|c|c|}
\hline Species & $p$ & $K^{I X}$ & $K^{O c c}$ \\
\hline $\mathrm{Cs}$ & 0.403 & 0.264 & 2.03 \\
\hline $\mathrm{Na}$ & 0.705 & 1.3264 & 0.3961 \\
\hline $\mathrm{Li}$ & 0 & 1 & 1 \\
\hline $\mathrm{K}$ & 1.24 & 0.948 & 0.346 \\
\hline $\mathrm{Rb}$ & 1.45 & 0.256 & 1.6 \\
\hline $\mathrm{Sr}$ & 0.528 & 8.5 & 0.147 \\
\hline $\mathrm{U}$ & 1.56 & 272 & 0.21 \\
\hline $\mathrm{Nd}$ & 1.31 & 4710 & 0 \\
\hline $\mathrm{Ce}$ & 0.788 & 209 & 0 \\
\hline $\mathrm{Ba}$ & 0.897 & 54.3 & 0.0782 \\
\hline $\mathrm{La}$ & 0.36 & 9.62 & 0.767 \\
\hline $\mathrm{Pr}$ & 0.482 & 14.9 & 0 \\
\hline $\mathrm{Y}$ & 0.0127 & 0.327 & 2.35 \\
\hline & & & \\
\hline
\end{tabular}

The mathematical approach to applying the equilibrium model is different for predicting an equilibrium condition than it is for simply estimating parameters based on measured equilibrium conditions. This approach is described below.

Let $\mathbf{X}_{\mathbf{e}}$ be the equilibrated salt composition in moles. The loading per unit cell of the zeolite can be represented by $\mathbf{y}_{\mathbf{e}}$. A function, g, exists that can be used to predict $\mathbf{y}_{\mathbf{e}}$ based on $\mathbf{X}_{\mathrm{e}}$.

$$
\mathbf{y}_{\mathbf{e}}=g\left(\mathbf{X}_{\mathbf{e}}\right)
$$


The mathematics behind this function can be found in the paper by Yoo et al. [ref. 1]. The total moles of each species in the zeolite can be represented by $\mathbf{Y}_{\mathbf{e}}$, where $\mathbf{Y}_{\mathbf{e}}$ can be calculated based on $\mathbf{y}_{\mathbf{e}}$ and the moles of zeolite unit cells $\left(\mathbf{x}_{\mathbf{z}}\right)$.

$$
\mathbf{Y}_{\mathbf{e}}=x_{z} \mathbf{y}_{\mathbf{e}}
$$

Then a mass balance can be formulated based on initial moles in salt $\left(\mathbf{X}_{\mathbf{i}}\right)$ and initial zeolite loading $\left(\mathbf{y}_{\mathbf{i}}\right)$.

$$
\mathbf{X}_{\mathbf{i}}=\mathbf{X}_{\mathrm{e}}+\mathbf{Y}_{\mathbf{e}}-x_{z} \mathbf{y}_{\mathbf{i}}
$$

To calculate $\mathbf{X}_{\mathbf{e}}$, a function must be found that estimates equilibrium conditions based on initial conditions and the equilibrium function $\mathrm{g}$.

$$
\mathbf{X}_{\mathbf{e}}=f\left(\mathbf{X}_{\mathbf{i}}, \mathbf{y}_{\mathbf{i}}, x_{z}, g\right)
$$

There are numerous reasonable choices of the function $\mathrm{f}$. The approach selected to calculate $\mathbf{X}_{\mathbf{e}}$ is to minimize the difference between the total initial and total final moles using the following equation with a constraint that the components of $\mathrm{X}$ are non-negative. By checking the minimization index converges to zero, the mass balance is assured and the resulting argument $\mathrm{X}$ can be claimed as a solution.

$$
\hat{\mathbf{X}}_{\mathbf{e}}=\arg \min _{\mathbf{X}}\left\|x_{z} g(\mathbf{X})+\mathbf{X}-\mathbf{X}_{i}-x_{z} \mathbf{y}_{\mathbf{i}}\right\|^{2}
$$

\section{A3.2.2 Comparison Between Model and Experimental Results}

Table A3.2.2 shows the initial mole fraction distribution in the salt, the measured final mole fraction distribution in the salt, and the predicted final distribution based on the equations given above.

Table A3.2.2. Initial and final mole fraction distributions for the ER salt used in the zeolite-A ion exchange experiment.

\begin{tabular}{|l|r|r|r|}
\multicolumn{1}{|c}{ Salt } & \multicolumn{1}{c}{$\begin{array}{c}\text { Initial mole } \\
\text { fraction }\end{array}$} & $\begin{array}{c}\text { Measured } \\
\text { final mole } \\
\text { fraction }\end{array}$ & \multicolumn{1}{c}{$\begin{array}{c}\text { Predicted } \\
\text { final mole } \\
\text { fraction }\end{array}$} \\
$\mathrm{LiCl}$ & 0.559 & 0.556 & 0.556 \\
$\mathrm{KCl}$ & 0.356 & 0.358 & 0.356 \\
$\mathrm{NaCl}$ & 0.0446 & 0.0500 & 0.0495 \\
$\mathrm{RbCl}$ & $8.07 \mathrm{E}-05$ & $7.83 \mathrm{E}-05$ & $7.99 \mathrm{E}-05$ \\
$\mathrm{CsCl}$ & $2.66 \mathrm{E}-04$ & $2.59 \mathrm{E}-04$ & $2.55 \mathrm{E}-04$ \\
$\mathrm{SrCl}_{2}$ & 0.00198 & 0.00196 & 0.00192
\end{tabular}




\begin{tabular}{|l|r|r|r|}
$\mathrm{BaCl}_{2}$ & 0.00280 & 0.00278 & 0.00275 \\
$\mathrm{YCl}_{3}$ & 0.00223 & 0.00195 & 0.00217 \\
$\mathrm{CeCl}_{3}$ & 0.00568 & 0.00509 & 0.00548 \\
$\mathrm{LaCl}_{3}$ & 0.00304 & 0.00271 & 0.00295 \\
$\mathrm{NdCl}_{3}$ & 0.00971 & 0.00860 & 0.00907 \\
$\mathrm{PrCl}_{3}$ & 0.00265 & 0.00240 & 0.00260 \\
$\mathrm{SmCl}_{3}$ & 0.00280 & 0.00258 & 0.00262 \\
$\mathrm{UCl}_{3}$ & 0.00296 & 0.00185 & 0.00292 \\
$\mathrm{PuCl}_{3}$ & 0.00589 & 0.00540 & 0.00582 \\
$\mathrm{NpCl}_{3}$ & $7.18 \mathrm{E}-05$ & $6.10 \mathrm{E}-05$ & $7.10 \mathrm{E}-05$ \\
\hline
\end{tabular}

Based on Table A3.2.2, the percent change in salt composition is plotted in Figure A3.2.2. A direct comparison is made between the measured and predicted changes. As can be seen, the ion exchange process was much more effective than predicted for the rare earths and actinides. It is recognized as possible that the actinides and lanthanides may have also removed from the salt via chemical reaction with oxygen-bearing materials, thus forming oxide dross or oxichlorides. The formed oxides and oxichlorides are insoluble to the salt and may completely avoid interacting with the zeolite phase, while some may remain in the zeolite phase and block the sorption of chloride species. Or the difference may be due to inadequate data involving rare earths being used for fitting the model parameters. 


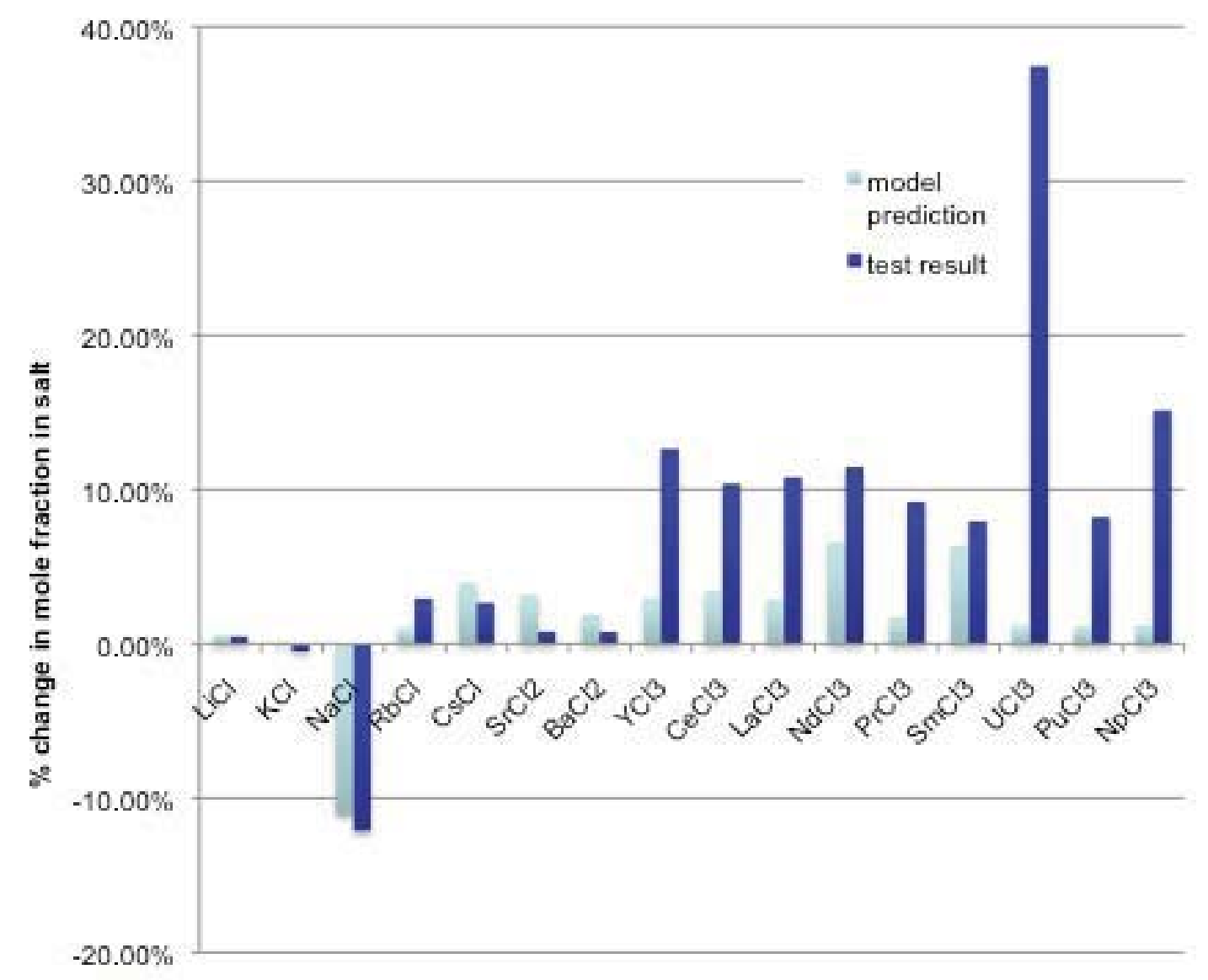

Figure A3.2.2. Comparison of model prediction to measured result for ER salt ion exchange test based on change in salt composition.

An alternative way of comparing experiment to model prediction for the ion exchange test involving electrorefiner salt is depicted in Figure A3.2.3. In this case, the comparison is done with zeolite loading numbers (equivalents per unit cell). For the experiment, the composition of the zeolite was not actually measured. It can be inferred via a mass balance on the salt. But this is seen as being inherently vulnerable to experimental error. Small error in the salt measurement can lead to absurd calculations for the loading in the zeolite. Rather than compare the model's prediction for zeolite loading to a mass balance derived experimental result for the zeolite loading, the model was also used to calculate the loading for the experimental result case. The function $g$ was used to calculate $\mathbf{y}_{\mathbf{e}}$ based on $\mathbf{X}_{\mathbf{e}}$ (as shown above). See Figure 3 for the results of this comparison. Note that the actinides were grouped and treated as only $\mathrm{U}$, since that is the only actinide for which model parameter estimation had been done. Likewise, Sm was grouped with $\mathrm{Nd}$. 


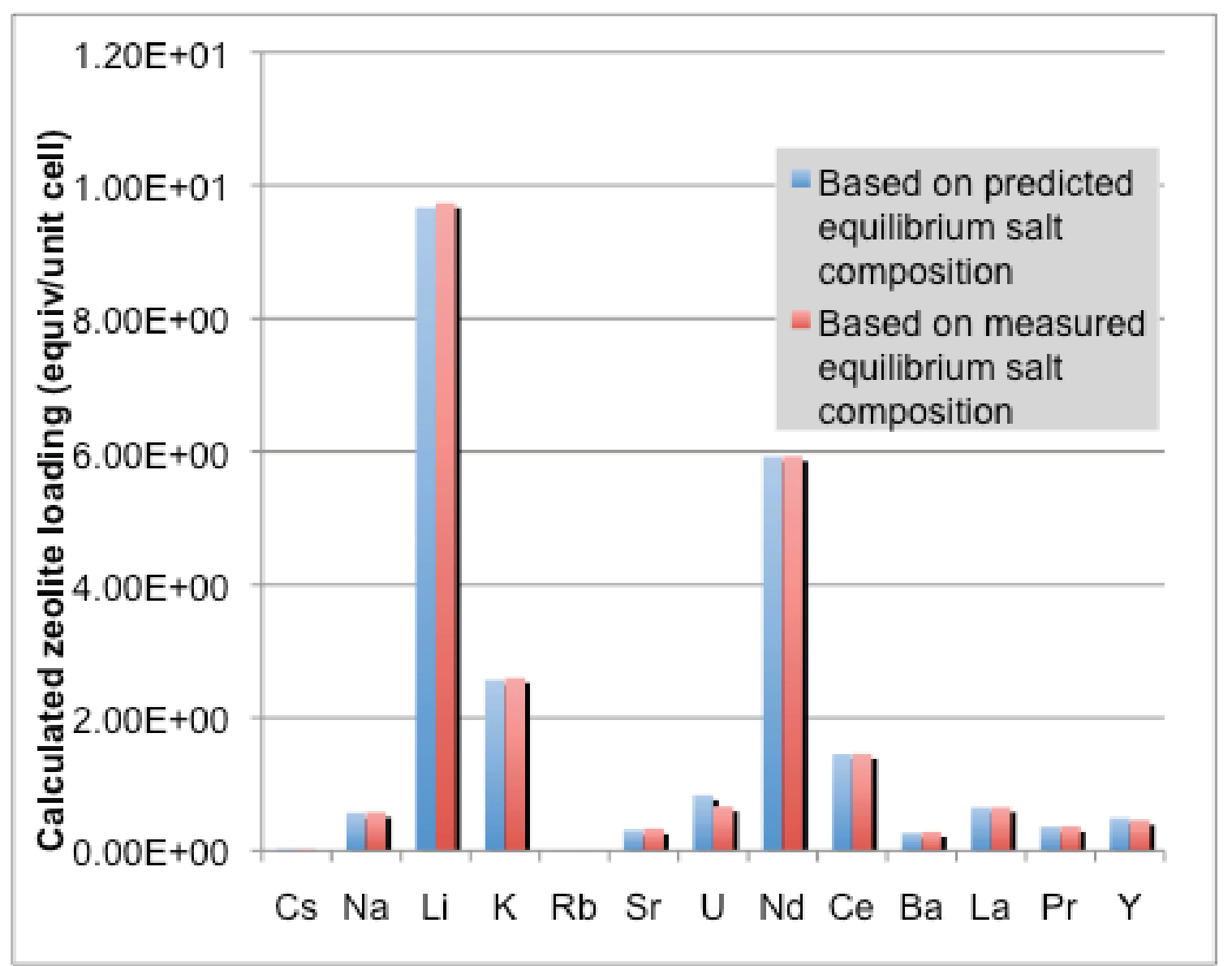

\section{Figure A3.2.3. Comparison of modeled zeolite loading based on measured salt composition versus predicted salt composition.}

In this case, the comparison actually looks quite favorable. And it leads to an entirely different conclusion - that the equilibrium model does a favorable job of predicting the experimental result. The question then naturally arises as to why the two different methods of comparison lead to such strikingly different conclusions. What is believed to be the case is that the loading of cations in the zeolite is relatively insensitive to the differences in salt composition between measured and experimental. Refer back to Table A3.2.2. There appears to be a striking difference between the $\mathrm{Nd}$ predictions, for example. The difference in salt composition between initial and final measured is $11.4 \%$, while the model predicts a significantly lower change of $6.6 \%$. This may seem like a large discrepancy between the result and the prediction. But the difference between the measured and predicted concentration for $\mathrm{Nd}$ is only 5.5\%. As seen in Figure A3.3.3, this leads to nearly identical predictions for the loading in the zeolite.

\section{A3.2.3 Conclusions}

Comparison of the results from the ion exchange experiment with electrorefiner salt with what the equilibrium ion exchange model predicts appears to indicate better than expected removal of rare earths and actinides. But further analysis suggests that the difference is actually quite small and insignificant with respect to loading in the zeolite. 
At this point, it is concluded that the equilibrium model that was developed with ternary and quaternary surrogate salt systems can be extended fairly well to multi-component systems, including electrorefiner salt. If zeolite ion exchange is considered for additional process development, the recommendation is that more experiments with a full spectrum of salt species be performed to provide additional data for more solid conclusions. It should also be considered that actinides, in particular, might be depleted via side reactions other than ion exchange. Experiments to test and quantify this phenomenon should be considered.

\section{$\underline{\text { References }}$}

1. T.S. Yoo, S.M. Frank, M.F. Simpson, P.A. Hahn, T.J. Battisti, and S. Phongikaroon; "Salt-Zeolite Ion Exchange Equilibrium Studies for Complete Set of Fission Products in Molten LiCl-KCl;" Nuclear Technology, accepted for publication.

\section{Task C3 - Final separations technology assessment (KAERI/INL)}

In the third year of this I-NERI project, four separation options were investigated by the KAERI and INL research groups. The four separation options are as follows.

A. Ion exchange with zeolite-A to remove all radionuclides

B. Oxidative precipitation for rare earths followed by ion exchange with zeolite-A for Group I and II radionuclides

C. Oxidative precipitation for rare earths followed by ion exchange with analcime for cesium (and possibly other Group I radionuclides) followed by zeolite-A for Group II radionuclides

D. Oxidative precipitation for rare earths followed by zone-freezing for Group I and II radionuclides.

These options are illustrated in Figure C3.1, and their functionality is summarized in Table C3.1. Options B and C are, in essence, modifications of Option A with oxygen sparging used to first remove rare earths. As oxygen sparging is extremely effective in removing rare earths, these modifications can be beneficial when the cleaned salt stream is required to have an extremely low rare earth concentration. But since zeolite-A has a relatively high selectivity for rare earths, options $\mathrm{B}$ and $\mathrm{C}$ introduce additional step to the overall process without the added benefit of significant waste minimization. The bases for selecting an optimal process for fission product separation should include waste volume minimization and process simplicity. Option $\mathrm{D}$ is unique in that it completely departs from using zeolite or any ion exchange material in the process. The potential benefit of this approach is a dramatic improvement in waste volume minimization 


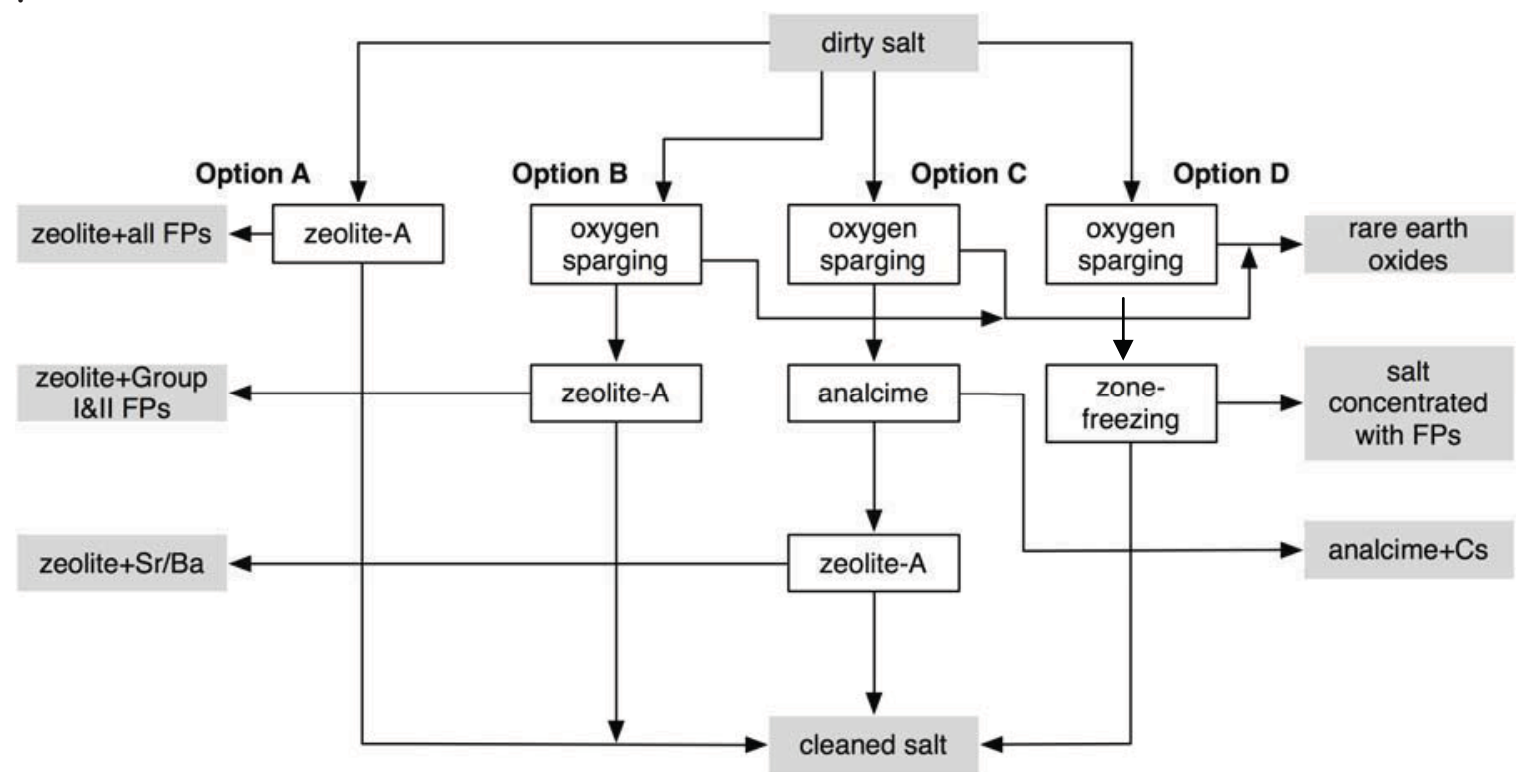

Figure C3.1. Schematic of the four most promising fission product separation options

Table C3.1. Summary of Functionality of Proposed Unit Operations for Fission Product Separations from Salt.

\begin{tabular}{|l|l|l|l|}
\hline Unit Operation & $\begin{array}{l}\text { Target Fission } \\
\text { Products }\end{array}$ & $\begin{array}{l}\text { Waste Form } \\
\text { Options }\end{array}$ & $\begin{array}{l}\text { Comments } \\
\text { Exchange } \\
\text { products } \\
\text { sodalite }\end{array}$ \\
\hline $\begin{array}{l}\text { Analcime Ion } \\
\text { Exchange }\end{array}$ & Cs & $\begin{array}{l}\text { Relatively low fission } \\
\text { product loading to the } \\
\text { waste form and } \\
\text { marginally clean salt; } \\
\text { High selectivity for rare } \\
\text { earths and actinides; } \\
\text { Leads to most mature } \\
\text { waste form type; } \\
\text { Operation in a hot cell } \\
\text { demonstrated }\end{array}$ \\
\hline Oxygen Sparging & Rare earths & $\begin{array}{l}\text { Glass waste form; } \\
\text { metal waste form }\end{array}$ & $\begin{array}{l}\text { Efficient Cs removal at } \\
\text { high concentration. }\end{array}$ \\
\hline $\begin{array}{l}\text { Extremely effective at } \\
\text { rare earth removal; Will } \\
\text { react with residual } \\
\text { actinides; Operation in a } \\
\text { hot cell demonstrated. }\end{array}$ \\
\hline Zone-Freezing & Group I\&II & $\begin{array}{l}\text { Glass-bonded } \\
\text { sodalite; SAP }\end{array}$ & $\begin{array}{l}\text { Effective removal of } \\
\text { Group I\&II; Behavior in } \\
\text { presence of rare earths } \\
\text { viewed as unpredictable; }\end{array}$ \\
\hline
\end{tabular}




\begin{tabular}{|l|l|l|}
\hline & & $\begin{array}{l}\text { Operation in a hot cell } \\
\text { may be problematic; } \\
\text { Discharged waste salt } \\
\text { will include a } \\
\end{array}$ \\
& considerable amount of \\
& $\begin{array}{l}\text { LiCl-KCl, so a waste } \\
\text { form capable of high salt } \\
\text { loading such as SAP } \\
\text { may be required. }\end{array}$ \\
\hline
\end{tabular}

While none of the options can be eliminated at this time, it does appear that Options A and D should be considered as preferred options for future investigation. Option A offers superior simplicity and demonstrated operability in a hot cell while being coupled to a mature waste form - the glass-bonded sodalite waste form developed for EBR-II spent fuel treatment. Meanwhile, Option D offers the greatest potential for waste volume reduction. Removal of rare earths via precipitation of their oxides offers outstanding waste volume reduction potential. It must be emphasized, however, that there is insufficient data at this time to eliminate any of the options. It is also important to state that several assumptions have been made in arriving at this recommendation. These include the following.

- Actinides can be sufficiently removed from the salt via a drawdown process so as to have little or no impact on the fission product separation unit operations or actinide loading to the waste form.

- A zone-freezing furnace can be effectively operated and controlled in a hot cell environment with high heat-emitting salt.

- In the case of sodium-bonded fuel, sodium chloride concentration in the ER salt can be regulated via using one or more of the separations unit operations.

- Iodine separation can be effectively removed by one of the separations unit operations, an assumption that has not been tested to date.

- Metal fuel has been assumed to be the feed into the process. If an oxide fuel is used, the Cs and Sr would likely be removed upstream of the electrorefiner and it may be possible to achieve all of the needed separations via oxygen sparging.

Efficient fission-product separation from electrorefiner salt that will result in highlevel waste minimization is a critical goal for the successful development of spent fuel treatment by the electrochemical/pyrometallurgical process. This project has been tremendously successful in that it has produced a wealth of information on several viable options for achieving fission-product separation. Each institution has made outstanding contributions to the project. And it is expected that these efforts will soon result in successful completion of the development of and implementation of process unit operations that will greatly improve pyroprocessing technology. 